\title{
A Mechanism Design Model of Firm Dynamics: The Case of Limited Commitment
}

\author{
Hengjie Ai, Dana Kiku, and Rui Li *
}

September 17, 2013

We present a general equilibrium-mechanism design model with two-sided limited commitment that accounts for the observed heterogeneity in firms' investment, payout and CEO-compensation policies. In the model, shareholders cannot commit to holding negative net present value projects, and managers cannot commit to compensation plans that yield life-time utility lower than their outside options. Firms operate identical constant return to scale technologies with i.i.d. productivity growth. Consistent with the data, the model endogenously generates a power law in firm size and a power law in CEO compensation. We also show that the model is able to quantitatively explain the observed negative relationship between firms' investment rates and size, the positive relationship between firms' size and their dividend and CEO payout, as well as variation of firms' investment and payout policies across both size and age.

\footnotetext{
*We would like to thank Xavier Gabaix, Zhiguo He, Dmitry Livdan, Erzo Luttmer, Vincenzo Quadrini, Adriano Rampini, Vish Vishwanathan for their helpful comments on the paper. We also thank seminar participants at the American Finance Association 2013 Meeting, the 2013 Minnesota Macro-Asset Pricing Conference, the 2013 Kellogg Finance Conference, the 1st Macro Finance Workshop, and the Finance department of University of Wisconsin at Madison.
} 


\section{Introduction}

It has been documented in the literature that the distribution of firm size and the distribution of CEO compensation obey power law. The elasticity of CEO pay with respect to firm size is about $1 / 3$, and this elasticity is U-shaped with respect to firm size: it is larger for firms in the left and right tails of the size distribution, and smaller for medium sized firms. It is also well known that small firms invest dis-proportionally more and pay out much less when compared with large firms. What is the economic mechanism that explains the tremendous amount of heterogeneity in firms' policies and their dependence on firm size? How does the cross-sectional characteristics of firm behavior inform us about the dynamic mechanism of firm growth? In this paper, we develop a general equilibrium model with heterogenous firms and two-sided limited commitment. We take a mechanism design approach and explore the implications of the constrained efficiency on firm dynamics. We show that two-sided limited commitment accounts for many salient features of the cross-sectional heterogeneity of firms' investment, payout, and CEO compensation policies.

The key elements of our model are: constant return to scale technology, i.i.d. productivity growth, and two-sided limited commitment. We assume that shareholders cannot commit to negative net present value projects, and that managers cannot commit to wage contracts that result in life-time utility lower than their outside option.

The main implications of our model can be summarized as follows. First, it generates a positive relationship between CEO pay and firm size and a U-shaped elasticity of CEO pay with respect to size, as in the data. We show that under the optimal contract, CEO compensation stays constant as long as none of the commitment constraints binds, rises after a sequence of positive productivity shocks, and shrinks after a series of negative shocks. A sequence of positive productivity shocks increases the value of the manager's outside option and forces shareholders to raise the level of compensation to retain the manager. Thus, manager compensation increases whenever his commitment constraint binds. A sequence of negative shocks lowers the value of the firm. To prevent bankruptcy, manager's wage has to drop whenever the value of the firm approaches zero, where the commitment constraint on the shareholder side binds. As a result, our model generates a positive relationship between CEO pay and firm size. In addition, this positive relationship is more likely to be present in firms in the right and left tails of the size distribution, where the limited commitment constraint tend to bind on the manager and the shareholder side, respectively.

Second, our model endogenously produce power laws in firm size and CEO compensation. Given that technologies are constant return to scale, firm growth follows a process similar to the discrete time processes studied in Kesten (1973) and Saporta (2005) and results in a 
fat-tailed distribution in firm size. ${ }^{1}$ Because managers' outside option rises with firm size, their compensation under the optimal contract has to increase accordingly. Consequently, the power law in firm size translates into a power law in CEO pay under the optimal contract. ${ }^{2}$

Third, we show further that our model predicts an inverse relationship between investment rate and firm size, and a positive relationship between dividend payout and firm size as in the data. Limited commitment on shareholder side implies that investment rate is higher than its first best level in small firms, where the NPV of the firm is close to zero, and the commitment constraint is more likely to bind. Because a binding constraint is associated with pay reductions and destroys the perfect risk sharing plan, it creates additional incentives for small firms to invest to avoid further downsizing. Conversely, the commitment constraint on manager side tends to bind in large firms where managers' outside options are more attractive. To reduce the likelihood of a binding constraint, it is optimal for large firms to avoid the outside option of managers to growth too fast by reducing investment. As a result, small firms in our model invest more and grow faster than large firms. For the same reason, small firms have low dividend yields as they typically spend most of their resources on funding investment. Both implications are consistent with the observed cross-sectional patterns in firms' investment and dividend choices.

We calibrate our model to match standard macroeconomic moments and volatility of output at the firm level and show that it can quantitatively account for the key moments of the joint distribution of firms' size, investment, payout and CEO-compensation policies observed in the data. We also show that, despite its simplicity, our model has rich implications for investment and payout behavior conditional on both firm size and age, and explains a significant amount of the cross-sectional variation in firms' decisions conditional on the two characteristics.

We show that both types of limited commitment, on the shareholder side and on the manager side, are important for understanding empirical relationships among CEO compensation, firms' investment and size. To highlight their importance, we first discuss the standard neoclassical model without contracting frictions. Because managers are risk averse and shareholders are well diversified, the optimal contract in this framework features complete risk sharing and a constant manager compensation. Due to convex adjustment costs, all firms here have the same investment-to-capital ratio and identical expected growth rates. Hence, this is a model where Gibrat (1931)'s law holds and the distribution of firm size obeys power law. However, it also implies a zero correlation between CEO pay and firm size

\footnotetext{
${ }^{1}$ See also Gabaix (2009) and Benhabib, Bisin, and Zhu (2011).

${ }^{2}$ As we show in the paper, CEO compensation under the optimal contract behaves like a linear function of the running maximum of firm size. CEO pay features a fat tailed distribution because the running maximum of the firm growth process obeys a similar power law.
} 
and rules out any dependence of firm growth rate on size. Modeling limited commitment on the shareholder side provides a theory for endogenous bankruptcy and generates an inverse relationship between investment and size. However, as in the frictionless case, risk sharing implies that $\mathrm{CEO}$ compensation never rises under the optimal contract, and consequently there is no power law in CEO pay. We demonstrate how our model with two-sided limited commitment improves upon the above models and explains important stylized features of the cross-sectional data.

Our paper builds on the large literature on limited commitment and its implications for firm behavior. ${ }^{3}$ Early contributions include Kehoe and Levine (1993), Kocherlakota (1996) and Kiyotaki and Moore (1997). Albuquerque and Hopenhayn (2004) provide a theoretical foundation for limited commitment models of firm dynamics. More recently, Lorenzoni and Walentin (2007) study the implications of limited commitment on the investment-Q relationship. Rampini and Viswanathan (2010, 2012) focus on firms' risk management and capital structure decisions. Lustig, Syverson, and Van Nieuwerburgh (2011) consider a model with one-sided limited commitment and study the link between the inequality of CEO compensation and productivity growth. Schmid (2008) studies the quantitative implications of limited commitment on firm financing and investment decisions in a neoclassical model. Our model differs from the above literature in several respects. We solve the mechanism-design problem with two-sided limited commitment in a generalequilibrium setting. Other models typically focus on limited commitment on the agent side only. We use continuous-time method to characterize the solution to the optimal contract and the cross-sectional distribution of firms as ordinary differential equations, which allows for sharper analytical results and efficient numerical solutions. In addition, none of above mentioned papers attempts to explain the power law in firm size and CEO compensation and their interaction. ${ }^{4}$ More generally, we confront our model with a comprehensive set of cross-sectional characteristics summarized in Section I.

A recent paper by Cooley, Marimon, and Quadrini (2012) considers a discrete-time model with two-sided limited commitment and study its implications on the size of the financial sector and compensation of financial executives. From the modeling perspective, the form of limited commitment on the shareholder side in our model differ from theirs. In their model, shareholders cannot commitment to any compensation plans that provides higher utility than managers' outside option. As a result, managers always receive their outside options in their model with two-sided limited commitment. We consider the case where shareholders cannot

\footnotetext{
${ }^{3}$ Our paper is also related to previous work that study the implications of dynamic agency on firms' investment and financing decisions, for example, Quadrini (2004), Clementi and Hopenhayn (2006), and DeMarzo and Fishman (2007a).

${ }^{4}$ Lustig, Syverson, and Van Nieuwerburgh (2011) is an exception. Their model also produces a power law for the distribution of firm size.
} 
commitment to negative NPV projects, and the optimal contract allows risk sharing. In addition, they do not consider the implications of their model on firm dynamics and the power law in firm size and CEO compensation.

The continuous-time methodology of this paper builds on the fast growing literature of continuous time dynamic contracting and firm decisions, for example, Sannikov (2008), DeMarzo and Sannikov (2006), DeMarzo, Fishman, He, and Wang (2009), He (2009), Biais, Mariotti, and Villeneuve (2010). For an excellent survey of this literature, see Biais, Mariotti, Plantin, and Rochet (2004). ${ }^{5}$ The solution of the optimal dynamic contract in our paper is based directly on Ai and Li (2013). Unlike this paper, Ai and Li (2013) do not consider the mechanism design problem, and do not study the quantitative implications of the model.

Our paper is also related to the literature on power law in firm size and CEO compensation. Gabaix (2009) surveys power law in economics and finance. Recent literature on firm dynamics and power law is reviewed in Luttmer (2010). Luttmer (2007) proposes a general equilibrium model where firms' growth rate is i.i.d. and the equilibrium size distribution obeys power law. The neoclassical model without frictions considered in this paper is essentially an interpretation of Luttmer (2007) with neoclassical production technology. Tervio (2003) and Gabaix and Landier (2008) are assortative matching models that link CEO compensation to firm size. ${ }^{6}$ Our model provides an alternative, mechanismdesign based explanation of the level of CEO pay and its dependence on firm size. Tervio (2003) and Gabaix and Landier (2008) study CEO compensation taking size distribution of firms as given. In our model, both the distribution of firm size and CEO compensation are endogenous outcomes of the optimal dynamic contract. An additional advantage of our dynamic model is that it can be used to study the cross-sectional distribution as well as the life-cycle dynamics of firms' investment, CEO compensation and dividend payout policies.

The rest of the paper is organized as follows. In Section I, we summarize the key stylized features of the joint empirical distribution of firms' size, age, investment, dividend payout and CEO compensation policies. In Section II, we consider a frictionless Arrow-Debreu economy and discuss its implications. We augment the baseline model with limited commitment on the shareholder side in Section III and further extend it to the case of two-sided limited commitment on both the principle and the agent side in Section IV. We demonstrate how these frictions improve upon the basic neoclassical model. Section V evaluates the quantitative implications of our model with two-sided limited commitment against the set of stylized facts documented in Section I. Section VI concludes.

\footnotetext{
${ }^{5}$ See also See also Tchistyi (2006), DeMarzo and Fishman (2007b), Piskorski and Tchistyi (2010), Zhu (Forthcoming), He (2009), Grochulski and Zhang (2011), and Miao and Zhang (2013).

${ }^{6}$ For a survey on the literature of the economics of super stars, see Gabaix and Landier (2008).
} 


\section{Stylized Facts}

We begin with a brief summary of the empirical distribution of firms' size, their investment, payout, and CEO compensation policies. The theoretical framework we develop in subsequent sections is aimed at providing a coherent interpretation of the observed features of the crosssectional data. The details of our empirical analysis and additional evidence are provided in Section VI.

1. The right tails of firm size and CEO compensation obey a power law. ${ }^{7}$ Firm size is characterized by a power-law distribution with an exponent of about 1.1. The distribution of CEO compensation is approximated by a power law with a slope coefficient of around 1.7 .

2. The elasticity of $\mathrm{CEO}$ pay with respect to firm size is close to $1 / 3{ }^{8}$ The elasticity is U-shaped in size: it is larger in the tails and lower in the middle of firm-size distribution.

3. Small firms invest at a higher rate compared with large firms. The average investmentto-capital ratio of firms in the top size decile is about $10 \%$. Small firms (those in the bottom decile of size distribution) have an average investment rate of around $17 \%$.

4. Small firms are less likely to make dividend and/or interest payments than large firms. In the bottom size decile, on average, only one out of ten firms have non-zero payouts. The fraction of dividend- and/or interest-paying firms increases to more than $80 \%$ in the right tail of firm size distribution.

We will keep this evidence as a reference when discussing the qualitative implications of the models that we lay out in following sections. In Section VI, we calibrate our benchmark model with two-sided limited commitment and formally evaluate its ability to account for these and other cross-sectional characteristics of the data.

\section{A General Equilibrium Model with Limited Commitment}

In this section, we set up a general equilibrium model with heterogeneous firms and limited commitment.

\footnotetext{
${ }^{7}$ The power law of the size distribution is well documented in the literature, for example, see Axtell (2001).

${ }^{8}$ See Roberts (1956), Baker, Jensen, and Murphy (1988), and Frydman and Saks (2010).
} 


\section{A Preferences}

Time is continuous and infinite. There are two types of agents, shareholders and managers. The representative shareholder is infinitely lived and her preference is represented by a time additive constant relative risk aversion utility:

$$
E\left[\int_{0}^{\infty} e^{-\beta t} \frac{1}{1-\gamma} \mathbf{C}_{t}^{1-\gamma} d t\right]
$$

where $\beta>0$ is the time discount rate, and $\gamma>0$ is the relative risk aversion coefficient. $\mathbf{C}_{t}$ denotes consumption flow rate of the shareholder at time $t$. Managers value consumption streams using the same preferences with identical risk aversion and time discount rate..$^{9,10}$

\section{B Production Technology}

Production in the economy takes place at a continuum of locations indexed by $j \in \mathcal{J}$, where $\mathcal{J}$ is the set of all possible locations. General output at location $j$ at time $t$, denoted by $y_{j, t}$, is produced using capital and labor though a Cobb-Douglas technology:

$$
y_{j, t}=K_{j, t}^{\alpha}\left(\mathbf{z}_{t} N_{j, t}\right)^{1-\alpha},
$$

where $K_{j, t}$ is the amount of capital and $N_{j, t}$ is the amount of labor at location $j$ and time t. $\mathbf{z}_{t}$ is the labor-augmenting productivity. We set $\mathbf{z}_{t}=\mathbf{z}$ to be constant in our theoretical model for simplicity but allow for aggregate productivity growth in calibration.

The representative shareholder owns all capital in the economy, supplies one unit of labor inelastically per unit of time, but does not have access to production technology. Managers are the only type of agents that have access to production technology. For simplicity, we assume that managers do not supply any labor.

Labor market is competitive. We focus on the stationary equilibrium where market prices are time-invariant. Let $\mathbf{W}$ denote the real wage and $\Pi(K)$ denote the operating profit function, that is,

$$
\Pi(K)=\max _{N}\left\{\mathbf{z} K^{\alpha} N^{1-\alpha}-\mathbf{W} N\right\}
$$

is the total revenue of a firm maximizing out labor input. Because the production technology is constant return to scale, and labor market is competitive, the operating profit function is

\footnotetext{
${ }^{9}$ Our model can be easily extended to incorporate the case where shareholders and managers have different time discount rate and/or different risk aversion. We do not entertain these extensions to maintain parsimony in our quantitative exercise.

${ }^{10}$ We refer to the shareholder as she and the manager as he in the rest of the paper.
} 
linear: $\Pi(K)=\mathbf{A} K$, where $\mathbf{A}$ is the economy-wide (equilibrium) marginal product of capital. Because labor market is perfectly competitive, equation (2) implies that firms' capital stock and total number of employees are proportional to each other in equilibrium. As a result, $K$ and $N$ are equivalent measures of firm size in our model.

The manager hired at location $j$ has access to a technology that accumulates capital according to the following law of motion:

$$
d K_{j, t}=\left(I_{j, t}-\delta K_{j, t}\right) d t+K_{j, t} \sigma d B_{j, t}
$$

where $\delta>0$ is the instantaneous depreciation rate of capital. The standard Brownian motion, $B_{j, t}$, is i.i.d. across locations and represents productivity shocks to the capital accumulation technology. ${ }^{11}$ The term $I_{j, t}$ is investment made at location $j$ at time $t$. Investing $I$ at a location with total capital stock $K \operatorname{costs} h\left(\frac{I}{K}\right) K$ of general output, where

$$
h(i)=i+h_{0} i^{2}
$$

is a strictly convex adjustment cost function.

\section{Entry and Exit of Firms}

A unit measure of managers arrives at the economy per unit of time. Upon arrival, a manager is endowed with an outside option that delivers life-time utility $\bar{U} \cdot{ }^{12}$ In order to operate a production technology for the shareholder, the manager must give up his outside option permanently.

The shareholder offers a contract to the manager upon his arrival. A contract is a plan for investment, managerial compensation, and dividend payout as a function of the entire history of the realization of productivity shocks. A firm is a contractual relationship between the manager and the shareholder organized for production at a particular location. We let $V(K, U)$ denote the value of a firm with total initial capital stock $K$ and the manager's promised utility $U$. Creating a firm of size $K$ requires a total cost of $H(K)$ in terms of current period consumption goods, where $H(\cdot)$ is a strictly increasing and a strictly convex cost function. At every point in time, the shareholder chooses the initial capital stock and the initial promised utility to the manager of a new generation of firms to maximize profit.

\footnotetext{
${ }^{11}$ We show in the Appendix of the paper that $K_{j, t}$ can be interpreted as the product of location specific productivity and location specific capital. In this case, Brownian motion $B_{j, t}$ can be interpreted as a combination of productivity shocks and capital depreciation shocks.

${ }^{12}$ For simplicity, we do not explicitly specify the technology that delivers the reservation utility. The outside option is never taken under our assumptions.
} 
As we show below, the value function $V(K, U)$ is strictly decreasing in $U$. Therefore, the optimal choice of the initial promised utility to the manager is $\bar{U}$, and the optimal initial size of new firms, denoted by $\bar{K}$, is given by:

$$
\bar{K} \in \arg \max \{V(K, \bar{U})-H(K)\}
$$

Managers are subject to random health shocks that follow a Poisson process with intensity $\kappa$. Once hit by a health shock, the manager exits the economy and all capital accumulated by the manager evaporates. Health shocks are i.i.d. across managers.

\section{Profit Maximization under Limited Commitment}

The economy we consider is one with overlapping generation of firms. At any point of time $t$,

a new generation of firms is created. We use $C_{j, t+s}^{t}, I_{j, t+s}^{t}$, and $D_{j, t+s}^{t}$ to denote the managerial compensation, investment, and dividend payout policy, respectively, for the generation- $t$ firms at location $j$ with age $s$. To save notation, we suppress the time index $t$, and consider the decision problem of a typical firm $j$ of age $s$.

Let $\mathbf{r}$ denote the equilibrium interest rate. Taking $\mathbf{r}$ as given, firm $j$ chooses a feasible contract $\left\{C_{j, s}, I_{j, s}, D_{j, s}\right\}_{s=0}^{\infty}$ to maximize the present value of dividend payments:

$$
E_{0}\left[\int_{0}^{\tau} e^{-\mathbf{r} s} D_{j, s} d s\right]
$$

where $E_{0}$ stands for expectation taken with respect to information available when the firm is at age 0 , and $\tau$ is the stopping time at which the manager of firm $j$ is hit by a Poisson health shock.

We restrict our attention to contracts that satisfy the resource constraint and make the manager at least as better off as his outside options. The resource constraint requires that managerial compensation, cost of investment (including adjustment cost), and dividend payment must not exceed the total operating profit:

$$
C_{j, s}+h\left(\frac{I_{j, s}}{K_{j, s}}\right) K_{j, s}+D_{j, s} \leq \Pi\left(K_{j, s}\right), \quad \text { for all } s \geq 0
$$

where $\Pi(K)$ is the operating profit function defined in equation (2). Note that we do not impose an exogenous nonnegativity constraint, $D_{s} \geq 0$. Rather, we let the optimal contract determine the amount of dividend payment. A negative dividend payment can be interpreted as equity issuance. 
To incentivize managers to work, the compensation plan $\left\{C_{j, s}\right\}_{s=0}^{\infty}$ must deliver a life-time utility at least as high as their outside options, $\bar{U}$ :

$$
\left\{E_{0}\left[\int_{0}^{\tau} e^{-\beta s}(\beta+\kappa) C_{j, s}^{1-\gamma} d s\right]\right\}^{\frac{1}{1-\gamma}} \geq \bar{U}
$$

Here we normalize the utility of the manager so that it is measured in the same units as consumption.

The key agency friction in our model is limited commitment, which restricts the set of feasible allocations. Formally, a contract $\left\{C_{j, s}, I_{j, s}, D_{j, s}\right\}_{s=0}^{\infty}$ is feasible if it satisfies equations (6) and (7) and the following two commitment constraints.

First, we assume that shareholders cannot commit to negative net present value projects. In this case, dividend policies that involve negative NPV of the firm at any point in time cannot be implemented. Limited commitment on the sharesholder side restricts the set of feasible plans and requires the dividend policy $\left\{D_{j, s}\right\}_{s=0}^{\infty}$ to satisfy:

$$
E_{s}\left[\int_{s}^{\tau} e^{-\mathbf{r}(t-s)} D_{j, t} d t\right] \geq 0, \text { for all } s \geq 0
$$

That is, the value of the firm must be non-negative at all times in all states of the world. Intuitively, a binding limited commitment constraint on the shareholder side implies zero firm value and can be interpreted as bankruptcy (Ai and Li (2013)).

Second, following Kehoe and Levine (1993), Kiyotaki and Moore (1997), and Albuquerque and Hopenhayn (2004), we assume that the manager has an option to default and cannot commit to compensation contracts that yield life-time utility lower than that provided by the outside option. Upon default, the manager can retain a fraction $\theta$ of the capital stock and hire labor in a competitive market to produce output. However, he is forever excluded from the credit market. That is, he can only consume the operating profit from the capital stock he absconds with upon default, but cannot enter into any intertemporal risk sharing contract. As we show in the appendix, the utility of the manager upon default is a linear function of the capital stock of the firm: $u_{M I N}(\theta) K_{s}$, where $u_{M I N}(\theta)$ is a function of $\theta$. Limited commitment on the manager side requires the compensation plan $\left\{C_{j, s}\right\}_{s=0}^{\infty}$ to satisfy:

$$
\left\{E_{s}\left[\int_{s}^{\tau} e^{-\beta(t-s)}(\beta+\kappa) C_{j, t}^{1-\gamma} d t\right]\right\}^{\frac{1}{1-\gamma}} \geq u_{M I N}(\theta) K_{s}, \text { for all } s \geq 0
$$

Any compensation plan that violates condition (9) will result in manager's default on the contract with positive probability. Default destroys risk sharing and implies a non-trivial welfare loss. As a result, efficiency require that we focus attention on plans that satisfy 
condition (9). A detailed characterization of $u_{M I N}(\theta)$ is given in Appendix B

To distinguish the two constraints, (8) and (9), in what follows we call the limited commitment constraint on shareholder side, equation (8), the bankruptcy constraint, and the limited commitment constraint on manager side, equation (9), the participation constraint.

\section{E General Equilibrium}

A competitive equilibrium must specify the path of interest rates, $\left\{\mathbf{r}_{t}\right\}_{t \geq 0}$, and wages, $\left\{\mathbf{W}_{t}\right\}_{t \geq 0}$, consumption of the representative shareholder, $\left\{\mathbf{C}_{t}\right\}_{t \geq 0}$, consumption, investment, and dividend payout policies for all firms at all times, $\left\{\left[\left(C_{j, t+s}^{t}, I_{j, t+s}^{t}, D_{j, t+s}^{t}\right)_{s=0}^{\infty}\right]_{t=0}^{\infty}\right\}_{j \in \mathcal{J}}$. We focus our attention on stationary equilibriums where the exit rate of firms equals the entry rate, and the cross-section distribution of firm characteristic is time-invariant. ${ }^{13}$ In this case, the interest rate and the wage rate are time-invariant. Using the results in Ai and $\mathrm{Li}$ (2013), the solution to the optimal contracting problem can be constructed by policy functions of state variables $(K, U)$, where $K$ is the total capital stock of the firm and $U$ is the continuation utility promised to the manager. Because policies depend only on the state variables $(K, U)$, we can think of them as a summary of firms' type. Using the language of Atkeson and Lucas (1992), the equilibrium allocation can be achieved by allocation rules:

$$
C(K, U), I(K, U), D(K, U), N(K, U), G(K, U)
$$

that are consistent with the policy functions of the dynamic contracting problem described in equations (5)-(9). Given the rules, allocations can be constructed by using a two-step procedure. First, for each firm of type $(K, U),\{C(K, U), I(K, U), D(K, U), N(K, U)\}$ specify the flow rate of manager's consumption, investment, dividend payout and amount of labor hired in the current instant. Next, the law of motion of the state variables is constructed from the allocation rules using:

$$
d K=K\left[\left(\frac{I(K, U)}{K}-\delta\right) d t+\sigma d B_{t}\right]
$$

and

$$
d U=\left[-\frac{\beta+\kappa}{1-\gamma}\left(C^{1-\gamma} U^{\gamma}-U\right)+\frac{1}{2} \gamma \frac{G(K, U)^{2}}{U}\right] d t+G(K, U) d B_{t} .
$$

Equation (11) follows the formulation in Sannikov (2008), except that we use a non-expected utility representation of the preference so that utility is measured in consumption units (equation 7).

\footnotetext{
${ }^{13}$ We prove the existence of such an equilibrium by construction.
} 
Formally, the equilibrium consists of interest rate, r, real wage, $\mathbf{W}$, allocation rules, $\{C(K, U), I(K, U), D(K, U), N(K, U), G(K, U)\}$, consumption of the representative shareholder, $\mathbf{C}$, and the cross-section distribution of types, $\Phi(K, U)$, such that:

1. Taking interest rates as given, the allocation constructed from the allocation rules described above solves the firm's optimal contracting problem that maximizes (5) subject to constraints (6)-(9).

2. The initial condition for news firms is $(\bar{K}, \bar{U})$, where $\bar{K}$ solves the profit maximization problem in equation (4).

3. Taking real wages as given, the policy function $N(K, U)$ solves the intra-temporal profit maximization problem in Equation (2) for all firms at all times.

4. The representative shareholder chooses consumption, investment in creating new firms, and investment and payout of existing firms to maximize utility in equation (1).

5. Goods market clears:

$$
\mathbf{C}+\int\left[C(K, U)+h\left(\frac{I(K, U)}{K}\right) K\right] d \Phi(K, U)+H(\bar{K})=\int K^{\alpha}(\mathbf{z} N)^{1-\alpha} d \Phi(K, U) .
$$

6. Labor market clears:

$$
\int N(K, U) d \Phi(K, U)=1
$$

7. The cross sectional distribution of types, $\Phi(K, U)$, is consistent with the law of motion of $(K, U)$ implied by the allocation rules, as in Equations (10) and (11). ${ }^{14}$

\section{F Normalized Continuation Utility}

The optimal contracting problem described in equations (5)-(9) is homogenous in the state variable $K$. Let $V(K, U)$ denote the value function of the optimal contracting problem, then homogeneity implies

$$
V(K, U)=v\left(\frac{U}{K}\right) K
$$

for some smooth function $v$. Define $u=\frac{U}{K}$ to be the normalized continuation utility. As shown in Ai and Li (2013), homogeneity of the optimal contracting problem implies that the

\footnotetext{
${ }^{14}$ Technically, $\Phi(K, U)$ must satisfy a version of the Komogorov forward equation as we show in the appendix.
} 
policy functions satisfy

$$
C(K, U)=c(u) K ; \quad I(K, U)=i(u) K
$$

for some continuous functions $c(\cdot)$ and $i(\cdot)$. The normalized value function, $v(u)$, can be characterized by the solution to an ordinary differential equation with appropriate boundary conditions, which we describe in detail in the appendix. In addition, due to homogeneity of decision rules, the two dimensional measure, $\Phi(K, U)$, in the market clearing conditions (12) and (6) can be replaced by a one-dimensional "summary measure" as described in Ai (2012). Together, the two ordinary differential equations (47) and (50) in Appendices C and $\mathrm{D}$ that characterize the normalized value function $v(u)$ and the summary measure $m(u)$, respectively, completely characterize the equilibrium.

The competitive equilibrium described above is constrained efficient subject to limited commitment constraints. In Appendix A, we show that the competitive equilibrium allocation is also the solution to some appropriately defined mechanism design problem. From this perspective, we take a mechanism design approach in this paper.

In the following sections, we first consider a first best economy with full commitment. We then examine how different forms of commitment frictions can account for the stylized facts 1-4 we outline in Section II in the context of our general equilibrium-mechanism design framework.

\section{First Best}

Firms' maximization problem in the first best case is as described in Section II.D except that constraints (8) and (9) do not apply. The profit maximization problem is separable and can be solved in two steps. The first is to maximize the total value of the firm

$$
E_{0}\left[\int_{0}^{\tau} e^{-\mathbf{r s}}\left[\mathbf{A} K_{s}-h\left(\frac{I_{s},}{K_{s}}\right) K_{s}\right] d s\right]
$$

subject to the law of motion of capital in equation (3) by choosing the optimal investment policy. In the second step, we choose $\left\{C_{s}\right\}_{s=0}^{\infty}$ to minimize the total cost of managerial compensation:

$$
E_{0}\left[\int_{0}^{\tau} e^{-\mathbf{r s}} C_{s} d s\right]
$$

subject to the promise keeping constraint in equation (7).

In the first best case, the firm value maximization problem (15) is standard as in Hayashi 
(1982). The solution to the cost minimization problem is straightforward: risk aversion of the manager and the fact that the principal and the agent have identical discount rates $(\mathbf{r}=\beta)$ imply a constant consumption of the manager: $C_{t}=\bar{U}$.

Proposition 1. The First-Best Case

The value function of the firm is given by:

$$
V(K, U)=\bar{v} K-\frac{1}{\mathbf{r}+\kappa} U
$$

where $\bar{v}=h^{\prime}(\hat{\imath})$ and $\hat{\imath}$ is the optimal investment-to-capital ratio given by:

$$
\hat{\imath}=\arg \max _{i \in\left[0, i_{A}\right]} \frac{\mathbf{A}-h(i)}{\hat{r}-i}=\hat{r}-\sqrt{\hat{r}^{2}-\frac{2}{h_{0}}(\mathbf{A}-\hat{r})} \in(0, \hat{r})
$$

with $\hat{r}=\mathbf{r}+\delta+\kappa$ and $i_{A}$ being the unique positive solution to $h(i)=\mathbf{A}$.

Proof. See Appendix C.

The term $\bar{v} K=h^{\prime}(\hat{\imath}) K$ in equation (17) is the firm value in the neoclassical model with capital adjustment cost, and $\frac{1}{\mathbf{r}+\kappa} U$ is the present value of manager's compensation. Perfect risk sharing implies a constant managerial compensation: $C_{t}=\bar{U}$ for all $t{ }^{15}$ therefore, the present value of the cost of managerial compensation is simply given by Gordon (1959)'s formula.

Equation (18) implies that the investment-to-capital ratio is constant across all firms. This results in a Gibrat's law in firm growth: growth rates are i.i.d. and do not depend on size. As a result, the model features a power law of the size distribution as in Luttmer (2007), which is summarized in the following proposition.

Proposition 2. Power Law of Firm Size

Given firms' initial size, $\bar{K}$, and their optimal investment policy, $\hat{\imath}$, the total measure of firms in the stationary equilibrium is $\frac{1}{\kappa}$ and the total amount of capital stock is

$$
\mathbf{K}=\frac{\bar{K}}{\kappa+\delta-\hat{\imath}} .
$$

\footnotetext{
${ }^{15}$ Recall that we normalize the utility function of the manager so that life-time utility is measured in consumption units.
} 
Furthermore, the density of firm size distribution is given by:

$$
\phi(K)= \begin{cases}\frac{1}{\sqrt{\left(\hat{\imath}-\delta-\frac{1}{2} \sigma^{2}\right)^{2}+2 \kappa \sigma^{2}}} \bar{K}^{-\alpha_{2}} K^{\alpha_{2}-1} & K \geq \bar{K} \\ \frac{1}{\sqrt{\left(\hat{\imath}-\delta-\frac{1}{2} \sigma^{2}\right)^{2}+2 \kappa \sigma^{2}}} \bar{K}^{-\alpha_{1}} K^{\alpha_{1}-1} & K<\bar{K},\end{cases}
$$

where $\alpha_{1}>\alpha_{2}$ are the two roots of the quadratic equation

$$
\kappa+\left(\hat{\imath}-\delta-\frac{1}{2} \sigma^{2}\right) \alpha-\frac{1}{2} \alpha^{2} \sigma^{2}=0 .
$$

In particular, the right tail of firm size obeys power law with exponent $\alpha_{2}$.

Proof. See Appendix D.

The first best model has several predictions. As shown in Proposition 2, this specification generates a power law in firm size. In addition, it implies an inverse relationship between the propensity of dividend payout and firm size. Both of these predictions are qualitatively consistent with the empirical evidence presented in Section I. Note that firms' cash flow, $\mathbf{A} K_{t}$, and their investment, $h(\hat{\imath}) K_{t}$, are proportional to size. Because managerial pay is constant in time series and in the cross section, total dividend payout, $D_{t}=(\mathbf{A}-\hat{\imath}) K_{t}-\bar{U}$, is high for large firms and low or even negative for small firms. ${ }^{16}$

Other implications of the first best model, however, are grossly inconsistent with the data. First, it predicts a flat investment-size relationship. Second, the distribution of CEO compensation is degenerate and hence the model generates a zero elasticity of managerial compensation with respect to size and cannot account for the observed fat tail in CEO pay.

\section{One-Sided Limited Commitment}

In this section, we allow for limited commitment on the shareholder side and assume that the shareholder cannot commit to negative NPV projects. Firms' profit maximization problem is described by equations (5)-(7) and the limited commitment constraint, (8). The key properties of the policy functions are summarized in Proposition 3 below. A complete characterization of the value and policy functions and technical details are provided in the appendix.

\section{Proposition 3. One-Sided Limited Commitment}

\footnotetext{
${ }^{16}$ These implications continue to hold in models with limited commitment as we discuss below.
} 
1. There exists $u_{M A X}>0$ such that under the optimal contract, $0<u_{t} \leq u_{M A X}$ for all $t$, and $v(u) \geq 0$ for all $u \in\left(0, u_{M A X}\right]$. In addition, the limited commitment constraint (8) binds at time $t$ if and only $u_{t}=u_{M A X}$.

2. The optimal compensation-to-capital ratio, $c\left(u_{t}\right)=\frac{C_{t}}{K_{t}}$ takes the following form:

$$
\ln c\left(u_{t}\right)=\ln C_{0}-\ln K_{t}-l_{t}^{-},
$$

where $\left\{l_{t}^{-}\right\}_{t=0}^{\infty}$ is the minimum increasing process such that $c\left(u_{t}\right) \leq c\left(u_{M A X}\right)$ for all $t$.

3. The optimal investment rate, $i(u)$, is a strictly increasing function of $u$. Also, $\lim _{u \rightarrow 0} i(u)=\hat{\imath}$, where $\hat{\imath}$ is the optimal investment level in the friction-less case.

Proof. Ai and Li (2013)

The optimal contract under limited commitment, as summarized in the above theorem, alters the implications of the fist best model along several dimensions.

First, firm value remains non-negative at all times. In Figure 1, we plot the normalized value function for the first best case (dash-dotted line), that for the one-sided limited commitment case (dashed line), and that for the twosided limited commitment case. In the first best case, $U_{t}=\bar{U}$ for all $t$. Therefore, the normalized utility, $u_{t}=\frac{\bar{U}}{K_{t}}$ can be arbitrarily large as $K_{t} \rightarrow 0$. Proposition 1 implies that the normalized value function is linear in the first best case: $v\left(u_{t}\right)=\bar{v}-\frac{1}{\mathbf{r}+\kappa} u_{t}$. As the size of the firm gets smaller, $u_{t} \rightarrow \infty$ and $v\left(u_{t}\right)$ becomes negative as illustrated in Figure 1. When shareholders cannot commit to negative NPV projects, as stated in part 1) of the above proposition, firm value is always non-negative and the promised utility $u_{t}$ stays in the interval $\left(0, u_{M a x}\right]$ at all times.

Second, managerial compensation is upward rigid: it decreases with negative productivity shocks as the limited commitment constraint binds, but never increases under the optimal contract. As a result, the elasticity of CEO compensation with respect to firm size is positive, but there will be no power law in CEO pay.

The optimal contract provides a constant compensation to the manager whenever firm value is strictly positive and involves a minimum necessary reduction in managerial compensation to keep the firm value non-negative whenever the shareholder's commitment constraint binds. Optimal risk sharing implies that compensation has to stay constant whenever the commitment constraint does not bind, and limited commitment requires a reduction in managerial compensation whenever firm value hits zero. This characterization of the optimal contract is formalized by Part 2 of the above proportion. 
Assume that the initial promised utility $u_{0}=\frac{\bar{U}}{\bar{K}}$ starts in the interior of $\left(0, u_{\text {Max }}\right]$. Denote $\tau$ the stopping time at which the limited commitment constraint binds, that is, $u_{t}=u_{M A X}$, for the first time. By part 2 of the above proposition, for $t<\tau, c\left(u_{t}\right)<c\left(u_{M A X}\right)$, and $l_{t}^{-}=0$. In this case, optimal risk sharing requires that $C_{t}=C_{0}$ and changes in $\ln C_{t}-\ln K_{t}$ be completely driven by $\ln K_{t}$. A sequence of negative productivity shocks lowers firm size, $K_{t}$ and increases $u_{t}=\frac{U_{t}}{K_{t}}$ toward $u_{M A X}$. At time $\tau, C_{\tau}=C_{0}$, and the shareholder's limited commitment constraint starts to bind: $v\left(u_{\tau}\right)=0$. On one hand, due to limited commitment, continued decreases in $K_{t}$ must be accompanied by reductions in CEO compensation. These pay cuts are implemented through increases in $l_{t}^{-}$that ensure $c\left(u_{t}\right) \leq c\left(u_{\text {Max }}\right)$ and $v\left(u_{t}\right) \geq 0$ for all $t .{ }^{17}$ On the other hand, further increases in $K_{t}$ moves $u_{t}$ away from $u_{M A X}$ and relaxes the commitment constraint. In the latter case, managerial compensation stays at the same level that was set last time the commitment constraint binds, until firm size reaches it previous running minimum, in which case the constraint starts to bind again. ${ }^{18}$ We can intuitively interpret the reduction in CEO pay as a default on a pre-agreed compensation contract and call the limited commitment constraint on shareholder side the bankruptcy constraint.

Clearly, $C_{0}=C(\bar{K}, \bar{U})$ is the maximum level of CEO compensation in the economy, and managers of all firms that have not experienced a binding bankruptcy constraint are paid $C_{0}$. As a result, there will be no power law in CEO pay.

Third, limited commitment on the shareholder side implies that firms' investment rate is decreasing in size, qualitatively consistent with stylized fact number 3 in Section I.

As stated in Proposition 3, investment is increasing in $u$. Intuitively, as capital stock gets depleted and the normalized utility goes up, the firm gets closer to the bankruptcy point $u_{M A X}$, which involves imperfect risk sharing and is welfare reducing. To avoid bankruptcy, the firm must increase investment to re-build its capital stock and move away from the distress region. Figure 2 plots the investment-to-capital ratio as a function of normalized utility $u$ in the first best case (dash-dotted line), that in the onesided limited commitment case (dashed line), and the same for the two-sided limited commitment case (solid line) for a fixed marginal product of capital, A. ${ }^{19}$ Consistent with Proposition 1, the investment rate $\left(\frac{I_{t}}{K_{t}}\right)$ is constant in the first best case. The investment rate under limited commitment on the shareholder side is always higher, and

\footnotetext{
${ }^{17}$ The increasing process $l_{t}^{-}$can be intuitively interpreted as the cumulative log pay reductions at time $t$.

${ }^{18}$ Managerial compensation under the optimal contract can be represented as a linear function of the running minimum of firm size. See Ai and $\mathrm{Li}$ (2013) for a formal argument of this result.

${ }^{19}$ For illustrative purposes, in Figure 1 and 2, we assume that the marginal product of capital is the same across all economies. Our comparison between the first best case and cases with limited commitment is a partial equilibrium one. In general equilibrium, fixing preference and technology parameters of the model and adding limited commitment will result in an endogenous change in the steady-state level of capital and, therefore, a different marginal product of capital.
} 
converge to that in the first best case as $u_{t} \rightarrow 0$. The fact that the investment rate is at least as high as that in the first best case implies that firms do not stop growing even after they become large, and the model is likely to generate a power law in firm size, as in the first best case.

Note that risk sharing implies promised utility is less sensitive to productivity shocks than firm size; therefore, firm size is negatively correlated with normalized utility, $u_{t}$ under the optimal contract. Hence, under limited commitment on the shareholder side, small firms invest more and feature higher growth rates compared with large firms.

\section{Two-Sided Limited Commitment}

In this section, we consider our full model with two sided limited commitment. In this case, managers have an outside option that delivers utility $u_{M I N} K_{t}$. Limited commitment on the manager side requires that the optimal contract has to satisfy managers' participation constraint, (inequality (9)): the continuation utility provided by the contract must be higher than that of the outside option at all times.

While limited commitment on the shareholder side affects mainly the optimal contract for small firms that are close to bankruptcy (through constraint (8)), limited commitment on the manager side primarily impact the dynamics of large firms, where the value of managers' outside option is high. As the size of the firm grows, so is the outside option of the manager, that is, the right hand side of the inequality (9). To discourage the manager from taking his outside option, compensation must rise. Limited commitment on the manager side, therefore, creates a mechanism where CEO compensation increases with firm size, and potentially allows our model to generate a power law in CEO compensation. The properties of the optimal compensation contract are summarized in the following proposition.

\section{Proposition 4. Two-Sided Limited Commitment}

1. There exists $u_{M A X}>0$ such that under the optimal contract, $u_{M I N} \leq u_{t} \leq u_{M A X}$ for all $t$. In addition, the limited commitment on the manager/shareholder side, (9)/(8) binds if and only if $u_{t}=u_{M I N} / u_{M A X}$.

2. Under the optimal contract, $u_{t}$ is decreasing in productivity shocks.

3. The optimal compensation-to-capital ratio, $c\left(u_{t}\right)=\frac{C_{t}}{K_{t}}$ takes the following form:

$$
\ln c\left(u_{t}\right)=\ln C_{0}-\ln K_{t}+l_{t}^{+}-l_{t}^{-},
$$


where the pair $\left\{l_{t}^{+}, l_{t}^{-}\right\}_{t=0}^{\infty}$ are the minimum increasing processes such that $c\left(u_{M I N}\right) \leq$ $c\left(u_{t}\right) \leq c\left(u_{M A X}\right)$ for all $t$.

4. The optimal investment rate, $i(u)$, is a strictly increasing function of $u$.

Proof. See Ai and Li (2013)

Part 1 and 2 of the above proposition characterize the dynamics of normalized continuation utility. In the two sided limited commitment case, $u_{t}$ must stay in the interval $\left[u_{M I N}, u_{M A X}\right]$. The participation constraint, (9) requires $U_{t} \geq u_{M I N} K_{t}$. In normalized utility terms, this constraint boils down to $u_{t} \geq u_{M I N}$, where $u_{M I N}$ is determined by the exogenous outside option of the manager. In addition, limited commitment on the shareholder side implies $u_{t} \leq u_{M A X}$, where $u_{M A X}$ is endogenously determined by the condition $v\left(u_{M A X}\right)=0$.

The normalized value function for the two-sided limited commitment case is plotted in Figure 1 as the solid line. Under two-sided limited commitment, the normalized utility is bounded away from zero by $u_{M} I N$, where the limited commitment constraint on the manager side binds. Clearly, more contracting frictions reduce the efficiency of risk sharing and lower the value functions. The value function for the two-sided limited commitment case lies under the value functions for the frictionless and for the one-sided commitment case. For the same reason, the maximum level of normalized utility $u_{M A X}$ in the two-sided limited commitment case is lower than that in the case of one-sided limited commitment. The lack of commitment on the manager side also limits the set of feasible continuation utilities that can be supported under the optimal contract.

We illustrate the dynamics of the state variable, $u_{t}$, under the optimal contract in Figure 3. The top panel of Figure 3 is the expected change, or the drift coefficient of $\ln u$ as a function of $u$. The bottom panel is volatility, or the diffusion coefficient of $\ln u$. The point $\bar{u}$ represents the average of normalized continuation utility across all firms in the stationary distribution. Note that under the optimal policy, the drift of $u$ reaches its maximum at $u_{M I N}$, and stays positive in the region close to $u_{M I N}$, indicating a tendency for $u_{t}$ to return to it steady state mean, $\bar{u}$, when $u_{t}$ is small. Similarly, the drift of $u$ achieves its minimum at $u_{M A X}$ and remains negative in regions close to $u_{M A X}$. This implies that $u_{t}$ tends to revert back to $\bar{u}$ when it is small. The pattern of the drift of $\ln u$ reveals that under the optimal policy, $u$ is a mean reverting process, and firms tend to accumulate in the area close to $\bar{u}$ in the long run.

The diffusion coefficient of $\ln u$ on the Brownian motion $d B_{t}$ is negative but above -1 . Note $u_{t}=\frac{U_{t}}{K_{t}}$. The Brownian productivity shocks $d B_{t}$ affect $K_{t}$ directly and impact $U_{t}$ indirectly through the optimal contract. Perfect risk sharing (first best) implies a diffusion 
coefficient of -1 : because continuation utility remains constant as $K_{t}$ moves with productivity shocks. In contrast, no risk sharing at all corresponds to a diffusion coefficient of 0 because continuation utility moves one for one with productivity shocks. A diffusion coefficient between -1 and 0 is the consequence of imperfect risk sharing: a positive productivity shock raises $K_{t}$ and $U_{t}$ simultaneously, but continuation utility $U_{t}$ is less sensitive to shocks. Note that the diffusion of $u_{t}$ tends to zero on the boundaries $u_{M I N}$ and $u_{M A X}$, indicating that risk sharing is poor when constraints are binding. In this case, normalized utility returns to the interior with probability one because it is completely driven by the drift term (top panel) as the diffusion term vanishes.

Part 3 of the above proposition implies that the optimal compensation contract inherits some properties from the one sided limited commitment case. In particular, managerial compensation must stay constant whenever none of the commitment constraints binds. It increases by a minimum amount to keep the manager from default when the manager's participation constraint binds, and drops by a minimum necessary amount to prevent firm value being negative when the bankruptcy constraint binds. Formally, the logarithm of compensation-to-capital ratio, $\ln c\left(u_{t}\right)$ can be obtained from $\ln C_{0}-\ln K_{t}$ by imposing a two-side regulator, $\left\{l_{t}^{+}, l_{t}^{-}\right\}_{t=0}^{\infty}$.

In Figure 4, we plot the sample path of a firm starting with a $u_{0}$ close to the bankruptcy point, $u_{M A X}$. The top panel in Figure 4 is the trajectory of the log size of the firm, $\ln K_{t}$, and the second panel is the path of the normalized utility, $u_{t}$. The third panel is the corresponding realizations of the value of the firm, $V\left(K_{t}, U_{t}\right)$, and the bottom panel shows the log managerial compensation, $\ln C_{t} \cdot{ }^{20}$ At time 0 , the firm starts from the interior of the normalized utility space, $u_{0}<u_{\text {MAX }}$. A sequence of negative productivity shocks from time 0 to time 2 lowers the capital stock of the firm (top panel). For $t<1, u_{t}<u_{M A X}$ is in the interior (second panel). In this region, firm value is strictly positive (third panel) and managerial compensation is constant (bottom panel). At $t=1, u_{t}$ hits the boundary $u_{M A X}$ and cannot increase further despite subsequent negative productivity shocks. For $t \in(1,2)$, the firm continues to receive a sequence of negative productivity shocks and the total capital stock of the firm shrinks (top panel). During this period, $u_{t}$ stays at $u_{M A X}$, where the bankruptcy constraint (8) binds, as shown in the second panel of Figure 4. The firm value remains at zero and does not cross over to the negative region due to reductions in managerial compensation, which keeps decreasing until the firm starts experiencing positive productivity shocks at time $t=2$. From time $t=2$ to $t=3$, the firm experiences a sequence of positive productivity shocks followed by a sequence of negative productivity shocks. As a result, firm value bounces back to the positive region and decreases afterwards (third panel). Because the normalized

\footnotetext{
${ }^{20} \ln K_{t}$ is a Brownian motion with drift, therefore its sample path is one with unbounded variation. We plot smooth sample paths for the convenience of illustrating the basic properties of the optimal contract.
} 
utility $u_{t}$ stays in the interior before $t=3$ (second panel), managerial consumption stays constant (bottom panel), although at a lower level than $C_{0}$. At time $t=3$ the size of the firm hits its previous running minimum, and $u_{t}$ reaches $u_{M A X}$ again. As before, firm value stays at zero, and managerial consumption keep decreasing, until the firm starts to receive positive productivity shocks for the next time.

In Figure 5, we plot a sample path of a firm with $u_{0}$ close to the left boundary, $u_{M I N}$, in Figure 5. The top panel is the realization of the $\log$ size of the firm, $\ln K_{t}$. The second panel is the path of the normalized utility, $u_{t}$. The third panel is the trajectory of the normalized value of the firm, $v\left(u_{t}\right)$, and the bottom panel is that of the log managerial compensation, $\ln C_{t}$. At time 0 , the firm starts from the interior of the normalized utility space, $u_{M I N}<u_{0}<u_{M A X}$. A sequence of positive productivity shocks from time 0 to 0.5 increases the capital stock of the firm (top panel). For $t<0.5, u_{t}>u_{M I N}$ is in the interior (second panel) and manager's consumption is constant (bottom panel). During this period, both the size of the firm, $K_{t}$ and the size-normalized firm value, $v\left(u_{t}\right)$, increases. At time 0.5 , the normalized continuation utility, $u_{t}$, reaches the left boundary, $u_{M I N}$, and the participation constraint binds. Further realizations of positive productivity shocks from $t=0.5$ to $t=1$ translate directly into increases in managerial compensation (bottom panel), but the normalized continuation utility (second panel), and the normalized firm value (third panel) remain constant. At time $t=1$, the firm starts to experience a sequence of negative productivity shocks. As a result, the size of the firm shrinks, and the normalize utility $u_{t}=\frac{U_{t}}{K_{t}}$ increases because risk sharing implies that the continuation utility $U_{t}$ is less sensitive to shocks than $K_{t}$ (part 3 of Proposition 4 ). During the period $t \in(1,3), u_{t}$ stays in the interior of $\left[u_{M I N}, u_{M A X}\right]$ and manager's consumption stays constant. At time $t=2$, the firm starts to receive a sequence of positive productivity shocks. During this period, $u_{t}$ stays in the interior of its domain until the size the firm, $K_{t}$, reaches its previous running maximum at $t=5$, in which case, the participation constraint starts to bind again, and manager's compensation increases as a result (bottom panel).

Limited commitment on manager side creates a mechanism through which managerial compensation increases with firm size. As the size of the firm increases, so is the outside option of the manager, $u_{M I N} K_{t}$. Eventually, the limited commitment constraint (9) binds and managerial compensation must increase with firm size to retain the manager. As we show in the calibration, this feature of the optimal contract allows our model to generate a power law in CEO compensation, as in the data.

By part 4 of the proposition, the optimal investment policy, $i(u)$ inherits the basic properties in the one-sided limited commitment case: it increases with normalized continuation utility. This is shown in Figure 2 as the solid line. Note 
that investment rate in both the one-sided commitment and the two sided commitment cases is an increasing function of $u$. However, in the one-sided limited commitment case, as $u \rightarrow 0$, $i(u) \rightarrow \hat{\imath}$, which is the optimal investment level in the frictionless economy. In the two-sided limited commitment case, on the other hand, $u$ is bounded by the manager's outside option, $u_{M I N}$. Moreover, as $u$ decreases, investment rate falls below the first best level, $\hat{\imath}$. It is optimal to invest at a level lower than $\hat{\imath}$ because a binding participation constraint is associated with inefficient risk sharing and therefore welfare reducing. To lower the manager's outside option and to reduce the probability of a binding participation constraint in the future, it is optimal to decrease investment and slow down firm growth. Because normalized continuation utility, $u_{t}$ is negatively correlated with firm size, small firms typically over-invest and large firms under-invest in the model with two sided limited commitment.

In the next section, we calibrate our model and show that two-sided limited commitment accounts for a wide range of stylized facts on firm investment, CEO compensation, and dividend payout, including those we listed in Section I of the paper.

\section{Quantitative Results}

\section{A Calibration and Simple Statistics}

We calibrate the model to match key macroeconomic statistics of the post-war U.S. data. The parameter values and the targeted moments are listed in Tables 1 and 2. In calibration, we allow for aggregate economic growth by setting $\mathbf{z}_{t}=\mathbf{z}_{0} e^{\mu t} \cdot{ }^{21}$ We choose $\mu=2 \%$ to match the average annual growth rate in the U.S. economy. We set risk aversion at 2 and assume a zero rate of time discount. Together with the assumed growth rate our preference configuration implies a $4 \%$ rate of return, which is approximately an average of equity and bond returns in the data. ${ }^{22}$

On the production side, following the macro literature, we set capital share, $\alpha$, at 0.33 . We choose capital adjustment cost parameter $\phi=5$ to match the average market-to-book ratio (Tobin's Q) in the data of about 1.7 . We calibrate the firm death rate, $\kappa$, at $5 \%$ to be consistent with the average exit rate. We choose capital depreciation $\delta=7 \%$ that, together with the death rate, implies a $12 \%$ effective depreciation rate of capital. We set the volatility parameter $\sigma=35 \%$ to match the average volatility of firms' sale growth rates in our data set. To ensure balanced growth, the cost of building new firms is assumed to be homogenous

\footnotetext{
${ }^{21}$ The solution of the model with a deterministic aggregate growth is a straightforward extension of the stationary model discussed in earlier sections. Details of the extended model are available upon request.

${ }^{22}$ Our calibration requires a discount rate of zero to avoid the well-known risk-free rate puzzle (Weil (1989)). Kocherlakota (1996) discusses the difficulty of matching asset return moments with standard expected utility.
} 
in aggregate capital. In particular, the cost function is specified as:

$$
H\left(K_{t}, \mathbf{K}_{\mathbf{t}}\right)=\frac{\psi_{0}}{1+\psi_{1}}\left(\frac{K_{t}}{\mathbf{K}_{\mathbf{t}}}\right)^{1+\psi_{1}} \mathbf{K}_{\mathbf{t}}
$$

We choose the parameters $\psi_{0}$ and $\psi_{1}$ so that the initial size of the generation-0 firms is normalized to one and the profit of setting up a new firm is zero.

We calibrate the equilibrium marginal product of capital, $\mathbf{A}$, to match the average investment-to-output ratio of $20 \%$ without explicitly specifying the initial level of aggregate productivity, $\mathbf{z}_{\mathbf{0}}$. Note that along the balanced growth path, aggregate investment must be related to aggregate capital stock by $\mathbf{I}_{\mathbf{t}}=(\mu+\kappa+\delta) \mathbf{K}_{\mathbf{t}}$. The output-to-investment ratio is then given by:

$$
\frac{\mathbf{Y}_{\mathbf{t}}}{\mathbf{I}_{\mathbf{t}}}=\frac{\mathbf{z}_{\mathbf{t}} \mathbf{K}_{\mathbf{t}}^{\alpha}}{(\mu+\kappa+\delta) \mathbf{K}_{\mathbf{t}}}=\frac{1}{\mu+\kappa+\delta} \mathbf{z}_{\mathbf{t}} \mathbf{K}_{\mathbf{t}}^{\alpha-1}
$$

Therefore, the equilibrium marginal product of capital can be calibrated directly to match the aggregate investment-to-output ratio:

$$
\mathbf{A}=\alpha \mathbf{z}_{\mathbf{t}} \mathbf{K}_{\mathbf{t}}^{\alpha-\mathbf{1}}=\alpha(\mu+\kappa+\delta) \frac{\mathbf{Y}_{\mathbf{t}}}{\mathbf{I}_{\mathbf{t}}}
$$

The magnitude of agency frictions in our model is determined by two parameters, managers' reservation utility, and the fraction of firms' asset that managers can abscond with upon default, $\theta$. To guarantee balance growth, we assume that the reservation utility of managers born at time $t$ is $e^{\mu t} \bar{U}$. We calibrate the parameter $\bar{U}=0.1107$ to roughly match the average CEO pay-to-output ratio in our sample. We set $\theta=1$ to follow Kehoe and Levine (1993)'s specification of the default technology. That is, upon default, managers can take off with $100 \%$ of firm's capital stock but are permanently excluded from the financial market.

After solving the model numerically, we simulate it out for 300 years, and discard the first 100 years of data. The model is continuous time, and all quantities are aggregated to the annual level. Our simulated sample consists of two million firms, which allows us to obtain tight estimates of various quantities of interest. Below, we present the crosssectional implications of our simulated model and discuss its ability to account for the key characteristics of the empirical distributions of firm size, CEO compensation, investment and dividend policies. The description and details of the empirical data are provided in the appendix. 


\section{B Power Law in Size and CEO Compensation}

It has been shown in the literature that firm size follows a power law distribution (for example, Axtell (2001), Gabaix (2009), and Luttmer (2007)). We confirm this evidence and show that the empirical distribution of CEO compensation is also fat-tailed. We describe the modelimplied distribution of size and managerial compensation and discuss how well our model can account for the right tail characteristics of the cross-sectional data.

Following Luttmer (2007) and Gabaix (2009), we use the following parametrization of power law. A distribution of random variable $X$ obeys power law if its density is governed by

$$
f(x)=k \zeta x^{-(1+\zeta)},
$$

for some constants $k, \zeta>0$. The complementary cumulative distribution function of $X$ is given by

$$
P(X>x)=k x^{-\zeta}
$$

The parameter $\zeta$ is called the power-law exponent.

Table 3 shows year-by-year estimates of the power-law parameter for firm size and CEO compensation. We measure size by the number of employees and estimate the slope of the right tail using data on the top 300 firms in a given year. ${ }^{23}$ Both firm size and CEO compensation conform to a power-law distribution with an average exponent of 1.1 and 1.7, respectively. Our estimates for size distribution are consistent with Luttmer (2007), who reports a power-law exponent of 1.07 using the total number of employees from the U.S. Census data. Gabaix and Landier (2008) measure firm size by market value and find comparable estimates of around one.

Consistent with the data, our calibrated model implies a power-law distribution of firm size with an exponent of about 1.09. Figure 6 provides a visual comparison of the tail behavior of the empirical and the model-implied distributions. The horizontal axis in the figure represents firm size and the vertical axis shows the complementary cumulative distribution function (both are equally spaced on the log scale). Under power law, the log-log plot is a straight line with a slope equal to the negative exponent. As the figure shows, the modelimplied slope matches quite well the slope observed in the data.

The right tail of CEO compensation in the model is distributed in virtually the same way as the that of firm size, with a power-law parameter of 1.09. Intuitively, in the model, CEO compensation in large firms is roughly a linear function of the running maximum of firm

\footnotetext{
${ }^{23} \mathrm{It}$ is common in the literature to fix the mass of the right tail to a pre-specified number of firms. We follow this tradition in Table 3. In the appendix, we present estimates of both parameters of power-law distribution (the exponent and the right-tail cutoff) and formally test the power-law null.
} 
size. $^{24}$ Because growth dynamics generate power law in the right tail of size distribution, the running maximum of the same process obeys a similar power law. That is, the optimal contract under limited commitment makes the power law in firm size translate into a similar power law in CEO compensation. Thus, our model provides an alternative explanation of power law in CEO compensation to the assortative matching model of Gabaix and Landier (2008).

Note that because the elasticity of managers' outside option with respect to firm size is assumed to be one, our model implies a fatter right tail of managerial compensation relative to the data. We illustrate the fit of the model in Figure 7 by presenting the complementary cumulative distribution function of CEO pay, side by side in the data and in the model. Both distributional plots are approximately linear on the log-log scale, but the model-implied slope is less steep compared with the data. Generalizing the outside option will potentially allow the model to better fit the right tail of the empirical distribution of CEO compensation.

\section{Cross-Sectional Characteristics of CEO Compensation}

The cross-sectional distribution of CEO compensation is characterized by several stylized features. Generally, managerial compensation tends to increase with firm size. However, size elasticity of CEO pay is not uniform and varies considerably with size.

As Table 4 shows, the average elasticity of CEO pay with respect to firm size in the data is about 0.32 and is largely similar across alternative measures of size. ${ }^{25}$ We find that the dependance of managerial pay on size is mostly driven by small and large firms, and is considerably weaker across medium-sized firms. The top panel of Figure 8 illustrates the variation in size elasticity of CEO compensation across five size-sorted portfolios. We consider four measures of size: market capitalization (stars), the number of employees (squares), capital (circles) and book value of assets (triangles). For all size measures, the elasticity is V-shaped - CEO compensation is more sensitive to size for firms in the left and in the right tails of size distribution.

The V-shape in size elasticity turns out to be a signature characteristic of our two-sided limited commitment model. In the model, CEO compensation varies with firm size either due to a binding bankruptcy constraint or a binding participation constraint. Because small firms tend to be close to the bankruptcy point, and large firms tend to face a binding participation constraint, CEO compensation is more sensitive to size for very small and very large firms. The bottom panel of Figure 8 shows the cross-sectional variation in size elasticity implied by

\footnotetext{
${ }^{24}$ In fact, as we show in Appendix E, in a model with limited commitment on manager side only, CEO compensation is exactly a linear function of the running maximum of firm size.

${ }^{25}$ Others report similar estimates of around one-third (see Gabaix (2009) for a survey of the literature).
} 
our model. Similar to the data, the model-implied elasticity is close to zero for medium-sized firms, and is quantitatively large for firms in the bottom and top size quintiles. Quantitatively, size elasticity of CEO compensation is equal to 0.99, 0.02 and 0.43 for firms in the first, third and fifth size sorted portfolios, respectively. On average, the elasticity of CEO compensation to firm size predicted by the model is about 0.24 , which is roughly similar to the empirical estimate.

We also find that controlling for firm size, the level of CEO compensation varies significantly with firm age. Table 5 reports the average level of CEO compensation for size and age sorted portfolios. We construct portfolios my sorting firms into three size groups, and dividing each size bin into three age-sorted portfolios. We find that in the data (shown in the top panel), the level of managerial compensation declines with firm age for small and medium-sized portfolios, but increases with age for large firms. On average, across small and medium-sized firms, CEOs in old firms earn about $40 \%$ less compared with managers in young firms. In contrast, managerial compensation in old big firms is about $30 \%$ larger than that in young big firms.

As shown in the bottom panel of Table 5, our model implies similar cross-sectional trends. To understand these patterns, it is important to note that CEO compensation in the model is history dependent and that firms, on average, grow. Consider first two small firms of different generations: a young and an old. To end up small, the old firm must have experienced a lot of negative productivity shocks, sufficient to offset its deterministic growth. Thus, the old firm is likely to have spent much more time in the bankruptcy region and is likely to have cut CEO compensation more frequently than the young one. As a result, across small firms, the model-implied CEO compensation in old firms is on average $45 \%$ lower than that in young firms. The situation is reversed for the large size cohort. While small old firms in the model represent losers, large old firms represent winners - these are firms that have experienced long-run growth and have come to face a binding participation constraint more often than their young counterparts. Consequently, consistent with the data, among large firms, the model-implied CEO compensation is increasing in age.

Table 6 shows the cross-sectional variation of CEO compensation as a percentage of firm size in the data (Panel A) and in the model (Panel B). Empirically, controlling for age, CEO pay-to-capital ratio declines with firm size. For example, among young firms, the ratio falls from $12.3 \%$ for small firms to $1.4 \%$ for large firms; among old firms, it declines from $4.2 \%$ to about $0.8 \%$ as size increases. Similarly, controlling for size, managerial compensation as a fraction of firm capital tends to decrease with age. The model features a similar crosssectional pattern.

In the model, the negative relationship between CEO pay-to-capital ratio and firm size is 
the implication of (imperfect) risk sharing under the optimal contract. Risk sharing reduces sensitivity of CEO compensation to productivity shocks. Therefore, as firms become large, $\mathrm{CEO}$ compensation as a fraction of their size declines. Also, as discussed above, age in the model is slightly negatively correlated with size for small firms and is positively correlated with size for large firms. As a result, in the cross-section of small firms, the pattern in CEO pay-to-capital ratio across age mimics the pattern in the level of CEO pay; for large firms, the cross-sectional pattern in CEO compensation-to-capital ratio is driven mostly by size. In all, similar to the data, the model-implied ratio of CEO compensation to capital is declining with age for all size cohorts.

\section{Cross-Sectional Distribution of Investment}

The inverse relationship between investment (and more generally growth rate) and size is one of the stylized features of the cross-sectional data - small firms, on average, invest at a much higher rate compared with large firms. Panel A of Figure 9 shows the empirical distribution of investment-to-capital ratio across 20 size-sorted portfolios. The average investment rate of the smallest percentile in the data is about $18 \%$, while firms in the top portfolio have an average investment-to-capital ratio of only $10 \%$. This evidence is consistent with Evans (1987) and Hall (1987) who document a negative relationship between firm growth and firm size. In our model, realized growth rates depend on both investment rate and productivity shocks but firms' expected growth is a function of investment rate only. Hence, differences in investment rates across firms translate directly into differences in average growth rates. We focus on investment rates because their measurement is less prone to selection biases. ${ }^{26}$

The distribution of investment rates implied by our model is plotted in the bottom panel of Figure 9. Consistent with the data, investment rate in the model monotonically declines from about $25 \%$ for small firms to almost $13 \%$ for firms in the very right tail of size distribution. As discussed above, limited commitment on the shareholder side makes it optimal for small firms to invest at a high rate to avoid sliding into bankruptcy. Thus, the rate of investment in the model is inversely related to firm size.

Table 7 characterizes the empirical distribution of investment rates across both size and age. For all age cohorts, investment rate in the data declines with size (Panel A). Similarly, controlling for size, average investment-to-capital ratio decreases with age. Quantitatively, per each unit of capital, small young firms invest twice more relative to large old firms. This evidence is consistent with findings in Davis, Haltiwanger, and Schuh (1996) and Cooley

\footnotetext{
${ }^{26}$ Observed realized growth rates of small firms may be high (even if expected growth rates are independent of firm size) because small firms hit by negative productivity shocks are more likely to drop out of the sample relative to large firms.
} 
and Quadrini (2001), who show that, controlling for the other characteristic, firm growth is negatively correlated with size and age.

The quantitative implications of our model for the cross-sectional distribution of investment rates across size and age, presented in Panel B of Table 7, are largely consistent with the data. Controlling for age, the model-implied investment rate is a decreasing function of firm size. Heterogeneity in firms' investment policy in the same age group reveals the key properties of the optimal contract in our model. Note that firms' realized growth has two components: a (locally) deterministic component that is due to investment, and a stochastic component that is due to productivity shocks. Firms in the same age group are similar in terms of the deterministic growth component and they differ in size mainly due to different realizations of productivity shocks. Controlling for age, large firms are those that received a good deal of positive productivity shocks; small firms, in contrast, are firms that were unlucky. To prevent bankruptcy and rebuild their capital, small firms choose much more aggressive investment policies compared with large firms. As a result, investment rate in the model decreases with size for all age cohorts and matches the pattern documented in the data.

Further, consistent with the data, the model-implied investment rate declines with age, especially for small firms. While all small firms invest at a high rate, younger ones have particularly strong incentives for investment and rapid growth because the managers' equity stake in these firms is the highest. As firms grow older, the managers' equity share tends to decline and so does their investment rate. This trend is also present among medium-sized and large firms, although it becomes less pronounced as the sensitivity of investment policy to the state variable (normalized utility) decreases outside the bankruptcy region.

\section{E Cross-Sectional Characteristics of Payout Policy}

Empirically, small firms are less likely to pay out dividends compared with large firms. Panel A of Figure 10 illustrates this evidence by plotting the fraction of dividend- and/or interestpaying firms across 20 size sorted portfolios. As the figure shows, the vast majority of small firms makes neither type of payments. In fact, only $10 \%$ of firms in the bottom size percentile pay dividends or make any interest payments. In contrast, almost nine out of ten firms in the top size portfolio pay either dividend or interest, or both. The fraction of non-zero paying firms increases almost monotonically across size-sorted portfolios. The corresponding model output is presented in Panel B. While the model-implied shape is somewhat different, overall, the model captures well the cross-sectional pattern observed in the data. Small firms in our model invest at a high rate and tend not to pay out dividends, whereas large firms invest less and pay out more frequently (effectively, most of the time). 
The model is also able to account for a strong positive correlation between dividend yields and firms' size. On average, dividend yields of small, median and large firms in the data are about $0.8 \%, 1.6 \%$ and $2.2 \%$ respectively. The model-implied dividend yields are also monotonically increasing in size. In fact, the net payout of small firms in the model is virtually zero as they use all available funds to accelerate investment and growth. Further, in the data, the positive relationship between dividend yields and size persists after controlling for firms' age, and conditional on size, older firms pay out more than younger ones. The model is fully consistent with the observed heterogeneity in dividend yields across double-sorted portfolios - in the model, controlling for the other characteristic, dividend yields increase with size and age.

\section{Conclusion}

We present a mechanism design model of firm dynamics. We start with a friction-less model with Arrow-Debreu contracts and illustrate how different forms of limited commitment on compensation contracts help explaining a wide range of empirical regularities in firms' investment, CEO compensation and dividend payout policies. We show that a simple model with two-sided limited commitment is consistent with key cross-sectional characteristics of firms' behavior.

Our goal is to build on the recent developments in continuous time contracting theory to develop a quantitative framework for firms using a mechanism design approach. Closing the model in general equilibrium allows us to use empirical evidence from the cross-section to discipline our dynamic model. Our model has predictions on both the time-series and the cross-sectional distribution of firms' decision that could be confronted with the data. We view limited commitment as the first step in building contracting frictions into dynamic general equilibrium models with heterogeneous firms. There are several aspects of our model that require improvement. At the moment, the model overstates the fat tail of CEO compensation, and it predicts zero pay-performance sensitivity for mid-sized firms. We believe that other frictions such as moral hazard and adverse selection could potentially help better align predictions of our model with the data. These are promising directions for future research.

UNIVERSITY OF MINNESOTA

UNIVERSITY OF ILLINOIS AT URBANA-CHAMPAIGN

University of Massachusetts Boston 


\section{Appendix}

\section{A Assumptions about the Parameters}

We make the following assumption which guarantees the first best investment to be strictly positive.

\section{Assumption 1.}

$$
\mathbf{A}>\beta+\delta+\kappa
$$

and

$$
i_{A}<\hat{r}
$$

with $\hat{r}=\mathbf{r}+\delta+\kappa$ and $i_{A}$ being the unique positive solution to $h(i)=\mathbf{A}$, namely $i_{A}=\frac{-1+\sqrt{1+2 h_{0} \mathbf{A}}}{h_{0}}<$ $\hat{r}$.

The following assumption implies that utility of the manager upon default is finite.

Assumption 2. If $\gamma<1$, then

$$
\frac{1}{2} \sigma^{2}<\frac{1}{\gamma}\left[\delta+\frac{1}{1-\gamma}(\theta \mathbf{A}-(\beta+\kappa))\right]
$$

alternatively, if $\gamma>1$, then

$$
\frac{1}{2} \sigma^{2}<\frac{1}{\gamma}\left[\frac{1}{\gamma-1}(\beta+\kappa)-\delta\right]
$$

\section{B Manager's Outside Option, $u_{M I N}(\theta)$}

Given a level of capital stock upon the manager's default, $K_{0}$, the manager maximizes his utility by making the following optimal investment and consumption decision.

$$
\max _{\left\{c_{t}, i_{t}\right\}_{t=0}^{\infty}}\left\{E\left[\int_{0}^{\tau}(\beta+\kappa) e^{-\beta t}\left(c_{t} K_{t}\right)^{1-\gamma} d t\right]\right\}^{\frac{1}{1-\gamma}}
$$

such that

$$
\begin{aligned}
c_{t}+h\left(i_{t}\right) & =\theta \mathbf{A} \\
d K_{t} & =K_{t}\left[\left(i_{t}-\delta\right) d t+\sigma d B_{t}\right]
\end{aligned}
$$

with $c_{t}=\frac{C_{t}}{K_{t}}$ and $i_{t}=\frac{I_{t}}{K_{t}}$. We adopt the utility representation of the same preference and define

$$
W\left(K_{0}, \theta\right)=\max _{\left\{c_{t}, i_{t}\right\}_{t=0}^{\infty}} E\left[\int_{0}^{\tau}(\beta+\kappa) e^{-\beta t} \frac{1}{1-\gamma}\left(c_{t} K_{t}\right)^{1-\gamma} d t\right] \text { for } \theta \in[0,1] .
$$


Then the function $W(\cdot, \theta)$ satisfies the following HJB differential equation.

$$
0=\max _{i}(\beta+\kappa)\left[\frac{((\theta \mathbf{A}-h(i)) K)^{1-\gamma}}{1-\gamma}-W(K, \theta)\right]+K(i-\delta) W_{K}(K, \theta)+\frac{1}{2} K^{2} \sigma^{2} W_{K K}(K, \theta) .
$$

Homogeneity of the optimization problem implies that $W(K, \theta)=\omega(\theta) K^{1-\gamma}$ for some function $\omega(\cdot)$, and the optimal investment to capital ratio and the consumption to capital ratio are constant across time which we denote as $i(\theta)$ and $c(\theta)$. Then (28) implies

$$
0=\max _{i}(\beta+\kappa) \frac{(\theta \mathbf{A}-h(i))^{1-\gamma}}{1-\gamma}+((1-\gamma) i-\hat{\beta}) \omega(\theta)
$$

with $\hat{\beta}=\beta+\kappa+\delta(1-\gamma)+\frac{1}{2} \gamma(1-\gamma) \sigma^{2}$. The first order condition of the maximization problem on the right hand side implies

$$
(\beta+\kappa) \frac{(\theta \mathbf{A}-h(i))^{1-\gamma}}{(1-\gamma) \omega(\theta)}=\frac{\theta \mathbf{A}-h(i(\theta))}{h^{\prime}(i(\theta))} .
$$

By plugging the above equality into (29), we have that $i(\theta)$ satisfies the equation of $\mathrm{x}, f(x)=0$, with

$$
f(x) \equiv \theta \mathbf{A}-h(x)+h^{\prime}(x)[(1-\gamma) x-\hat{\beta}] .
$$

We have the following lemma.

Lemma 1. Under Assumption 1 and $2, i(\theta)$ is the unique solution to $f(x)=0$ over $\left[0, i_{A}\right]$.

Proof. Since $h^{\prime}(i)>0$ for $i>0$ and $\theta \mathbf{A}-h(i(\theta)) \in[0, A-h(i(\theta))]$, so $i(\theta) \in\left[0, i_{A}\right]$. We prove that equation $f(x)=0$ has a unique solution over $\left[0, i_{\theta \mathbf{A}}\right]$. Notice that

$$
f^{\prime}(x)=-\left\{\gamma\left(1+h_{0} x\right)+h_{0} x \hat{\beta}\right\}
$$

First we consider the case with $\gamma<1$. It is straight forward to show that $f(x)<0$ over $\left(0, i_{\theta \mathbf{A}}\right)$ because (25) implies $i_{A}<\beta+\delta+\kappa$ which in turn implies $\hat{\beta}>0$. In addition, (26) implies that

$$
f(0)=\theta \mathbf{A}-\hat{\beta}>0
$$

and (24)

$$
f\left(i_{A}\right)=-h^{\prime}\left(i_{A}\right)\left[\beta-(1-\gamma)\left(i_{A}-\delta\right)+\frac{1}{2} \gamma(1-\gamma) \sigma^{2}\right]<0
$$

Therefore, continuity of $f(\cdot)$ implies the desired result. If $\gamma>1,(27)$ implies $\hat{\beta}>0$ and then $f^{\prime}(i)<0$ over $\left(0, i_{A}\right)$. (27) also implies $f(0)>0$ and $f\left(i_{A}\right)>0$. Consequently, continuity of $f(\cdot)$ implies the desired result in this case.

Notice that, as $h_{0} \rightarrow 0, i(\theta) \rightarrow h_{0}(\theta \mathbf{A}-\hat{\beta})$. Therefore, by solving the equation that $i(\theta)$ satisfies, 
we have

$$
i(\theta)=\frac{\frac{2}{\gamma}(\theta \mathbf{A}-\hat{\beta})}{\left(1-\frac{h_{0}}{\gamma} \hat{\beta}\right)+\sqrt{\left(1-\frac{h_{0}}{\gamma} \hat{\beta}\right)^{2}-4 h_{0}\left(\frac{1}{2 \gamma}-1\right)\left(\frac{1}{\gamma}(\theta \mathbf{A}-\hat{\beta})\right)}}
$$

and

$$
c(\theta)=\theta \mathbf{A}-h(i(\theta)) .
$$

Therefore $\omega(\theta)=[\theta \mathbf{A}-h(\theta)]^{-\gamma}\left(1+h_{0} i(\theta)\right)$ and $u_{M I N}(\theta)=\omega(\theta)^{\frac{1}{1-\gamma}} \theta$.

\section{Proof of Proposition 1}

As in $\mathrm{Ai}$ and $\mathrm{Li}$ (2013), due to homogeneity of the problem, we take the value function associated with the optimization problem of the first best investment policy to be $\bar{v} K$ and solve the constant $\bar{v}$ by the following HJB equation.

$$
(\mathbf{r}+\kappa) \bar{v}=\max _{i}\{\mathbf{A}-h(i)+(i-\delta) \bar{v}\} .
$$

The first order condition of the right hand side implies

$$
h^{\prime}(\hat{\imath})=\bar{v} \text { or } \bar{v}=1+h_{0} \hat{\imath}
$$

By plugging the above equation into (31), we have that $\hat{\imath}$ satisfies

$$
\frac{1}{2} h_{0} \hat{\imath}^{2}-h_{0} \hat{r} \hat{\imath}+(\mathbf{A}-\hat{r})=0 .
$$

Since as $h_{0} \rightarrow \infty, \hat{\imath} \rightarrow 0$, we have

$$
\hat{\imath}=\hat{r}-\sqrt{\hat{r}^{2}-\frac{2}{h_{0}}(\mathbf{A}-\hat{r})} .
$$

Notice that Assumption 1 guarantees the above expression to be well defined and, along with (31), implies

$$
\hat{\imath}=\arg \max _{i \in\left[0, i_{A}\right]} \frac{\mathbf{A}-h(i)}{\hat{r}-i} .
$$

\section{The Mechanism Design Interpretation of the Model}

The equilibrium notion we use in our main text is one of competitive equilibrium subject to limited commitment constraints. In this section, we provide a mechanism design interpretation of the model. We show that the competitive equilibrium allocation in our model is the solution to some appropriately defined mechanism design problem with limited commitment constraints. ${ }^{27}$

\footnotetext{
${ }^{27}$ Our construction here is similar to Theorem 1 in Atkeson and Lucas (1992). However, Theorem 1 in Atkeson and Lucas (1992) does not apply directly, because the definition of limited commitment on
} 
Let $\Psi$ be the set of all managers. $\forall \psi \in \Psi$, we use $t(\psi)$ to denote the stopping time at which manager $\psi$ arrives at the economy, and use $\tau(\psi)$ to denote the stopping time at which manager $\psi$ exit the economy. Denote $\Psi_{0}$ the set of managers active at time 0 . We set $t(\psi)=0$ if $\psi \in \Psi_{0}$.

An initial condition of the economy, $\left\{K_{0}(\psi)\right\}_{\psi \in \Psi_{0}}$ specifies the initial amount of capital of all managers active at time 0 . An allocation is denoted $\left\{\mathbf{C}_{t}, \overline{\mathbf{K}}_{t}\right\}_{t=0}^{\infty} ;\left\{\left\{C_{t}(\psi), I_{t}(\psi), N_{t}(\psi)\right\}_{t=0}^{\infty}\right\}_{\psi \in \Psi}$, where $\mathbf{C}_{t}$ is the consumption of the representative shareholder at time $t$, and $\overline{\mathbf{K}}_{t}$ is the initial size of firms built at time $t$. For $t \geq t(\psi), C_{t}(\psi), I_{t}(\psi)$, and $N_{t}(\psi)$ denote the consumption, investment, and amount of labor hired by manager $\psi$ at time $t .^{28}$ An allocation, $\left\{\mathbf{C}_{t}, \overline{\mathbf{K}}_{t}\right\}_{t=0}^{\infty}$; $\left\{\left\{C_{t}(\psi), I_{t}(\psi), N_{t}(\psi)\right\}_{t=0}^{\infty}\right\}_{\psi \in \Psi}$ is said to satisfy the resource constraint under initial condition $\left\{K_{0}(\psi)\right\}_{\psi \in \Psi_{0}}$ if

i) For all $t$,

$$
\mathbf{C}_{t}+H\left(\overline{\mathbf{K}}_{t}\right)=\int_{\Psi}\left[K_{t}^{\alpha}(\psi)\left(\mathbf{z} N_{t}(\psi)\right)^{1-\alpha}-h\left(\frac{I_{t}(\psi)}{K_{t}(\psi)}\right) K_{t}(\psi)-C_{t}(\psi)\right] d \psi,
$$

where for all $\psi, K_{t}(\psi)$ must satisfy

$$
d K_{t}(\psi)=\left[I_{t}(\psi)-\delta K_{t}(\psi)\right] d t+K_{t}(\psi) d B_{t}, \quad t \geq t(\psi)
$$

with the initial condition $K_{0}(\psi)$ given if $\psi \in \Psi_{0}$ and $K_{t(\psi)}=\overline{\mathbf{K}}_{t(\psi)}$ if $\psi \notin \Psi_{0}$.

ii) For all $t$,

$$
\int_{\Psi} N_{t}(\psi) d \psi=1
$$

Note that the above definition of resource constraint coincides with resource constraint (12) in the paper if policies are functions of state variables.

An allocation $\left\{C_{t}(\psi), I_{t}(\psi), N_{t}(\psi)\right\}_{s=0}^{\infty}$ is said to satisfy the participation constraint for manager $\psi$ with reservation utility $\bar{U}(\psi)$ if

$$
\left\{E_{t(\psi)}\left[\int_{t(\psi)}^{\tau(\psi)} e^{-\beta[s-t(\psi)]}(\beta+\kappa) C_{s}(\psi)^{1-\gamma} d s\right]\right\}^{\frac{1}{1-\gamma}} \geq \bar{U}(\psi)
$$

An allocation $\left\{C_{t}(\psi), I_{t}(\psi), N_{t}(\psi)\right\}_{t=0}^{\infty}$ is said to satisfy the limited commitment constraint for manager $\psi$ if for all $t \geq t(\psi)$

$$
\left\{E_{t}\left[\int_{0}^{\tau(\psi)} e^{-\beta s}(\beta+\kappa) C_{t+s}(\psi)^{1-\gamma} d s\right]\right\}^{\frac{1}{1-\gamma}} \geq u_{M I N} K_{t}(\psi)
$$

where the dynamics of $K_{t}(\psi)$ is given by (33). Note that participation constraint (35) is of the same shareholder side (8) contains equilibrium prices.

${ }^{28}$ Our convention is to set $C_{t}(\psi)=I_{t}(\psi)=N_{t}(\psi)=0$ if $t<t(\psi)$ or $t>\tau(\psi)$. 
form as the participation constraint (7) in the main text, and the limited commitment constraint (36) is identical to (9) in the main text.

An allocation $\left\{\mathbf{C}_{t}, \overline{\mathbf{K}}_{t}\right\}_{t=0}^{\infty} ; \quad\left\{\left\{C_{t}(\psi), I_{t}(\psi), N_{t}(\psi)\right\}_{t=0}^{\infty}\right\}_{\psi \in \Psi}$ is said to satisfy the limited commitment constraint for the shareholder if for any $t$,

$$
E_{t}\left[\int_{0}^{\infty} e^{-\beta s} \frac{1}{1-\gamma} \mathbf{C}_{t+s}^{1-\gamma} d s\right] \geq E_{t}\left[\int_{0}^{\infty} e^{-\beta s} \frac{1}{1-\gamma} \tilde{\mathbf{C}}_{t+s}^{1-\gamma} d s\right]
$$

for all continuation consumption profile $\left\{\tilde{\mathbf{C}}_{t+s}\right\}_{s=0}^{\infty}$ that satisfies for all $s$,

$$
\tilde{\mathbf{C}}_{t+s}+H\left(\overline{\mathbf{K}}_{t+s}\right)=\int_{\tilde{\Psi}}\left[K_{t+s}^{\alpha}(\psi)\left(\mathbf{z} \tilde{N}_{t+s}(\psi)\right)^{1-\alpha}-h\left(\frac{I_{t+s}(\psi)}{K_{t+s}(\psi)}\right) K_{t+s}(\psi)-C_{t+s}(\psi)\right] d \psi
$$

and

$$
\int_{\Psi} \tilde{N}_{t+s}(\psi) d \psi=1
$$

for some $\tilde{\Psi} \subseteq \Psi$ that is measurable with respect to date- $t$ information. The interpretation of (37) is that the shareholder can abandon any subset of managers at time $t$ based on available information and redeploy labor among all remaining firms. Unlike the limited commitment constraint (8) in the main text, condition (37) does not contain equilibrium prices. We are now ready to define feasibility and constrained efficiency.

Definition 1. (Constrained Efficiency)

An allocation $\left\{\mathbf{C}_{t}, \overline{\mathbf{K}}_{t}\right\}_{t=0}^{\infty} ;\left\{\left\{C_{t}(\psi), I_{t}(\psi), N_{t}(\psi)\right\}_{s=0}^{\infty}\right\}_{\psi \in \Psi}$ is said to be feasible if it satisfies the resource constraint (32), the limited commitment constraint, (36) for all $\psi \in \Psi$, and the limited commitment constraint for the shareholder, (37). It is said to be constrained efficient if there is no other allocation that makes all agents weakly better off, and at least a subset of agents of positive measure strictly better off.

Our goal is to show that competitive equilibrium allocations subject to the limited commitment constraints, (8) and (9), are constrained efficient. The difficulty is that constraint (8) contains equilibrium prices and is not equivalent to (37) in general. To solve this issue, we first define a notation of competitive equilibrium subject to limited commitment constraints, (36) and (37).

Definition 2. (Competitive Equilibrium with Limited Commitment)

An allocation $\left\{\widehat{\mathbf{C}}_{t}, \widehat{\mathbf{K}}_{t}\right\}_{t=0}^{\infty} ;\left\{\left\{\widehat{C}_{t}(\psi), \widehat{I}_{t}(\psi), \widehat{N}_{t}(\psi)\right\}_{t=0}^{\infty}\right\}_{\psi \in \Psi}$ is said to be a competitive equilibrium with limited commitment under the supporting price system $\left\{\mathbf{r}_{t}, \mathbf{W}_{t}\right\}_{t=0}^{\infty}$ and managers utility frontier, $\{\bar{U}(\psi)\}_{\psi \in \Psi}$ if:

1. Firms of all generations maximize profit. This include: 
i) For all $\psi \in \Psi_{0}$, the allocation $\left\{\widehat{C}_{t}(\psi), \widehat{I}_{t}(\psi), \widehat{N}_{t}(\psi)\right\}_{t=0}^{\infty}$ maximizes shareholder proft,

$$
E_{0}\left[\int_{0}^{\infty} e^{-\mathbf{r}_{t} t}\left[K_{t}^{\alpha}(\psi)\left(\mathbf{z} N_{t}(\psi)\right)^{1-\alpha}-\mathbf{W}_{t} N_{t}(\psi)-h\left(\frac{I_{t}(\psi)}{I_{t}(\psi)}\right)-C_{t}(\psi)\right] d t\right]
$$

subject to: 1) the initial condition of $\left.K_{0}(\psi) ; 2\right)$ the participation constraint (35); 3) The limited commitment constraint (36) and (37).

ii) For all $\psi \in \Psi \backslash \Psi_{0}$, let $t=t(\psi)$, the allocation $\widehat{K}_{t} ;\left\{\widehat{C}_{t+s}(\psi), \widehat{I}_{t+s}(\psi), \widehat{N}_{t+s}(\psi)\right\}_{s=0}^{\infty}$ maximizes shareholder proft,

$$
E_{t}\left[\int_{0}^{\infty} e^{-r_{t+s} s}\left[\begin{array}{c}
K_{t+s}^{\alpha}(\psi)\left(\mathbf{z} N_{t+s}(\psi)\right)^{1-\alpha}-\mathbf{W}_{t+s} N_{t+s}(\psi) \\
-h\left(\frac{I_{t+s}(\psi)}{I_{t+s}(\psi)}\right)-C_{t+s}(\psi)
\end{array}\right] d s \mid K_{t}\right]-H\left(K_{t}\right)
$$

subject to 1) the participation constraint (35); 2) The limited commitment constraint (36) and (37).

2. The consumption process $\left\{\widehat{\mathbf{C}}_{t}\right\}_{t=0}^{\infty}$ maximizes the representative shareholder's utility subject to the budget constraint:

$$
\int_{0}^{\infty} e^{-r_{t}} \mathbf{C}_{t} d t=P V+\int_{0}^{\infty} e^{-r_{t}} \mathbf{W}_{t} d t
$$

where we denote the present value of the profit from firm $\psi$ to be $P V(\psi)$, and $P V$ the total profit from all firms:

$$
P V=\int_{\Psi} e^{-r_{t(\psi)} t(\psi)} P V(\psi) d \psi
$$

3. The resource constraints, (32) and (34) are satisfied.

In what follows, we show that competitive equilibrium allocations subject to the limited commitment constraints, (36) and (37), are constrained efficient. This is formally stated in Lemma 1 below.

Lemma 2. Let $\left\{\widehat{\mathbf{C}}_{t}, \widehat{\mathbf{K}}_{t}\right\}_{t=0}^{\infty} ;\left\{\left\{\widehat{C}_{t}(\psi), \widehat{I}_{t}(\psi), \widehat{N}_{t}(\psi)\right\}_{t=0}^{\infty}\right\}_{\psi \in \Psi}$ be a competitive equilibrium allocation subject to limited commitment constraint (36) and (37), then it is constrained efficient.

Proof. Let $\left\{\widehat{\mathbf{C}}_{t}, \widehat{\mathbf{K}}_{t}\right\}_{t=0}^{\infty} ;\left\{\left\{\widehat{C}_{t}(\psi), \widehat{I}_{t}(\psi), \widehat{N}_{t}(\psi)\right\}_{t=0}^{\infty}\right\}_{\psi \in \Psi}$ be a competitive equilibrium allocation subject to limited commitment constraints, (36) and (37). Let $\left\{\mathbf{r}_{t}, \mathbf{W}_{t}\right\}_{t=0}^{\infty}$ be the supporting price system. We assume that the proposed allocation is Pareto dominated by an alternative feasible allocation $\left\{\mathbf{C}_{t}^{*}, \overline{\mathbf{K}}_{t}^{*}\right\}_{t=0}^{\infty} ;\left\{\left\{C_{t}^{*}(\psi), I_{t}^{*}(\psi), N_{t}^{*}(\psi)\right\}_{t=0}^{\infty}\right\}_{\psi \in \Psi}$ and prove by contraction.

Because all preferences are strictly monotone, we can without loss generality assume that all managers are weakly better off and the representative shareholder is strictly better off, that is,

$$
E\left[\int_{0}^{\infty} e^{-\beta s} \frac{1}{1-\gamma} \mathbf{C}_{s}^{* 1-\gamma} d s\right]>E\left[\int_{0}^{\infty} e^{-\beta s} \frac{1}{1-\gamma} \widehat{\mathbf{C}}_{s}^{1-\gamma} d s\right]
$$


This implies that the "*" allocation must violate the budget constraint for the shareholder, that is,

$$
\int_{0}^{\infty} e^{-r_{t} t} \mathbf{C}_{t}^{*} d t>\widehat{P V}+\int_{0}^{\infty} e^{-r_{t}} \mathbf{W}_{t} d t
$$

where $\widehat{P V}$ denotes the total profit from all firms under the "^" allocation. Let $P V^{*}$ denote the total profit of all firms under the "*" allocation, then profit maximization implies $\widehat{P V} \geq P V^{*}$. Therefore, inequality (40) implies

$$
\int_{0}^{\infty} e^{-r_{t} t} \mathbf{C}_{t}^{*} d t>P V^{*}+\int_{0}^{\infty} e^{-r_{t}} \mathbf{W}_{t} d t
$$

Using the definition of $P V^{*}$, the above implies

$$
\begin{aligned}
\int_{0}^{\infty} e^{-r_{t} t} \mathbf{C}_{t}^{*} d t> & \int_{\Psi} E_{0}\left[\int_{0}^{\infty} e^{-\mathbf{r}_{t} t}\left[K_{t}^{\alpha}(\psi)\left(\mathbf{z} N_{t}(\psi)\right)^{1-\alpha}-\mathbf{W}_{t} N_{t}(\psi)-h\left(\frac{I_{t}(\psi)}{I_{t}(\psi)}\right)-C_{t}(\psi)\right] d t\right] d \psi \\
& -\int_{0}^{\infty} e^{-r_{t}} H\left(\overline{\mathbf{K}}_{t}^{*}\right) d t+\int_{0}^{\infty} e^{-r_{t}} \mathbf{W}_{t} d t
\end{aligned}
$$

Using the resource constraint (34), we have:

$$
\int_{0}^{\infty} e^{-r_{t} t}\left[\mathbf{C}_{t}^{*}+H\left(\overline{\mathbf{K}}_{t}^{*}\right)\right] d t>\int_{\Psi} E_{0}\left[\int_{0}^{\infty} e^{-\mathbf{r}_{t} t}\left[K_{t}^{\alpha}(\psi)\left(\mathbf{z} N_{t}(\psi)\right)^{1-\alpha}-h\left(\frac{I_{t}(\psi)}{I_{t}(\psi)}\right)-C_{t}(\psi)\right] d t\right] d \psi
$$

which contradicts the resource constraint (32) for the "*" allocation.

We are now ready to show that the competitive equilibrium allocation we discuss in the paper is constrained efficient. As in the main text of the paper, we focus on stationary equilibria, where all prices and aggregate quantities are constant. We denote such an equilibrium as $\{\mathbf{C}, \overline{\mathbf{K}}\}$; $\left\{\left\{C_{t}(\psi), I_{t}(\psi), N_{t}(\psi)\right\}_{t=0}^{\infty}\right\}_{\psi \in \Psi}$. Note that in a stationary equilibrium we must have $\mathbf{r}=\beta$. Finally, we use $\mathbf{W}$ to denote the equilibrium wage.

Proposition 5. (Mechanism Design Interpretation of the Model)

Let $\{\widehat{\mathbf{C}}, \widehat{\overline{\mathbf{K}}}\}, \quad\left\{\left\{\widehat{C}_{t}(\psi), \widehat{I}_{t}(\psi), \widehat{N}_{t}(\psi)\right\}_{t=0}^{\infty}\right\}_{\psi \in \Psi}$ be a stationary competitive equilibrium allocation that satisfy conditions 1-7 in Section II.E of the paper. Then it is constrained efficient.

Proof. Let $\mathbf{W}$ be the equilibrium wage. In light of Lemma 2, we only need to show that $\{\widehat{\mathbf{C}}, \widehat{\overline{\mathbf{K}}}\}$, $\left\{\left\{\widehat{C}_{t}(\psi), \widehat{I}_{t}(\psi), \widehat{N}_{t}(\psi)\right\}_{t=0}^{\infty}\right\}_{\psi \in \Psi}$ constitutes a competitive equilibrium with limited commitment constraints (36) and (37). Because he competitive equilibrium defined in the text only differ from that in Definition 2 in condition (37) and (8), it is enough to show: i) The proposed allocation, $\left\{\left\{\widehat{C}_{t}(\psi), \widehat{I}_{t}(\psi), \widehat{N}_{t}(\psi)\right\}_{t=0}^{\infty}\right\}_{\psi \in \Psi}$ satisfies constraint (37); ii) Given $\mathbf{C}_{\mathbf{t}}=\widehat{\mathbf{C}}$ for all $t$, any allocation, $\left\{\left\{C_{t}(\psi), I_{t}(\psi), N_{t}(\psi)\right\}_{t=0}^{\infty}\right\}_{\psi \in \Psi}$ that satisfies constraints (35), (36), and (37) yields a lower profit than the proposed allocation, $\left\{\left\{\widehat{C}_{t}(\psi), \widehat{I}_{t}(\psi), \widehat{N}_{t}(\psi)\right\}_{t=0}^{\infty}\right\}_{\psi \in \Psi}$. To this end, it is enough to show that $\left\{\left\{C_{t}(\psi), I_{t}(\psi), N_{t}(\psi)\right\}_{t=0}^{\infty}\right\}_{\psi \in \Psi}$ also satisfies (8). 
We first prove i). Let $\left\{\tilde{\mathbf{C}}_{t+s}\right\}_{s=0}^{\infty}$ be any continuation consumption plan that satisfies (38) and (39). By the concavity of the utility function of the representative shareholder, we have

$$
E_{t}\left[\int_{0}^{\infty} e^{-\beta s} \frac{1}{1-\gamma} \widehat{\mathbf{C}}^{1-\gamma}-\frac{1}{1-\gamma} \tilde{\mathbf{C}}_{t+s}^{1-\gamma} d s\right] \geq E_{t}\left[\int_{0}^{\infty} e^{-\beta s} \mathbf{C}^{-\gamma}\left(\widehat{\mathbf{C}}-\tilde{\mathbf{C}}_{t+s}\right) d s\right]
$$

Note that because $\left\{\left\{\widehat{C}_{t}(\psi), \widehat{I}_{t}(\psi), \widehat{N}_{t}(\psi)\right\}_{t=0}^{\infty}\right\}_{\psi \in \Psi}$ is a competitive equilibrium allocation, $\widehat{K}_{t+s}^{\alpha}(\psi)\left(\mathbf{z} \widehat{N}_{t+s}(\psi)\right)^{1-\alpha}=\frac{1}{\alpha} \mathbf{A} \widehat{K}_{t+s}(\psi)$ for all $s$, where $\mathbf{A}$ is the equilibrium marginal product of capital. We have

$$
\begin{aligned}
\widehat{\mathbf{C}}-\tilde{\mathbf{C}}_{t+s}= & \int_{\Psi}\left[\frac{1}{\alpha} \mathbf{A} \widehat{K}_{t+s}(\psi)-h\left(\frac{\widehat{I}_{t+s}(\psi)}{\widehat{K}_{t+s}(\psi)}\right) \widehat{K}_{t+s}(\psi)-\widehat{C}_{t+s}(\psi)\right] d \psi \\
& -\int_{\widetilde{\Psi}}\left[\widehat{K}_{t+s}^{\alpha}(\psi)\left(\mathbf{z} \tilde{N}_{t+s}(\psi)\right)^{1-\alpha}-h\left(\frac{\widehat{I}_{t+s}(\psi)}{\widehat{K}_{t+s}(\psi)}\right) \widehat{K}_{t+s}(\psi)-\widehat{C}_{t+s}(\psi)\right] d \psi \\
\geq & \int_{\Psi \backslash \widetilde{\Psi}}\left[\mathbf{A} \widehat{K}_{t+s}(\psi)-h\left(\frac{\widehat{I}_{t+s}(\psi)}{\widehat{K}_{t+s}(\psi)}\right) \widehat{K}_{t+s}(\psi)-\widehat{C}_{t+s}(\psi)\right] d \psi
\end{aligned}
$$

by the concavity of production function. Note also $\mathbf{r}=\beta$; therefore, (41) and (42) together imply

$$
\begin{aligned}
& E_{t}\left[\int_{0}^{\infty} e^{-\beta s} \frac{1}{1-\gamma} \widehat{\mathbf{C}}^{1-\gamma}-\frac{1}{1-\gamma} \tilde{\mathbf{C}}_{t+s}^{1-\gamma} d s\right] \\
\geq & \int_{\Psi \backslash \tilde{\Psi}} \mathbf{C}^{-\gamma} E_{t}\left[\int_{0}^{\infty} e^{-\mathbf{r} s}\left(\mathbf{A} \widehat{K}_{t+s}(\psi)-h\left(\frac{\widehat{I}_{t+s}(\psi)}{\widehat{K}_{t+s}(\psi)}\right) \widehat{K}_{t+s}(\psi)-\widehat{C}_{t+s}(\psi)\right) d s\right] d \psi \\
\geq & 0,
\end{aligned}
$$

where the last inequality follows because condition (8) implies that for all $\psi$, $E_{t}\left[\int_{0}^{\infty} e^{-\mathbf{r} s}\left[\mathbf{A} \widehat{K}_{t+s}(\psi)-h\left(\frac{\widehat{I}_{t+s}(\psi)}{\widehat{K}_{t+s}(\psi)}\right) \widehat{K}_{t+s}(\psi)-\widehat{C}_{t+s}(\psi)\right] d s\right] \geq 0$.

To prove ii), let $\left\{\left\{C_{t}(\psi), I_{t}(\psi), N_{t}(\psi)\right\}_{t=0}^{\infty}\right\}_{\psi \in \Psi}$ be any allocation that satisfies (37). We need to show that for (almost every) $\psi$,

$$
E_{t}\left[\int_{0}^{\infty} e^{-\mathbf{r} s}\left(\mathbf{A} \widehat{K}_{t+s}(\psi)-h\left(\frac{\widehat{I}_{t+s}(\psi)}{\widehat{K}_{t+s}(\psi)}\right) \widehat{K}_{t+s}(\psi)-\widehat{C}_{t+s}(\psi)\right) d s\right] \geq 0 .
$$

Note that the total measure of managers is $1 / \kappa$ at any time. For a fixed $t$, let $\Psi=[0,1 / \kappa]$. Assume (44) is not true, and we prove by contradiction.

Let $\left(\psi_{0}, \psi_{0}+\epsilon\right)$ be an open ball in $\Psi$ such that

$$
E_{t}\left[\int_{0}^{\infty} e^{-\mathbf{r} s}\left(\mathbf{A} \widehat{K}_{t+s}(\psi)-h\left(\frac{\widehat{I}_{t+s}(\psi)}{\widehat{K}_{t+s}(\psi)}\right) \widehat{K}_{t+s}(\psi)-\widehat{C}_{t+s}(\psi)\right) d s\right]<0 \quad \text { a.e. }
$$


Define $f:(0, \epsilon) \rightarrow R$ such that

$$
f(\xi)=E_{t}\left[\int_{0}^{\infty} e^{-\beta s} \frac{1}{1-\gamma} \widehat{\mathbf{C}}^{1-\gamma}-\frac{1}{1-\gamma} \tilde{\mathbf{C}}_{t+s}^{1-\gamma}(\xi) d s\right]
$$

where

$$
\begin{gathered}
\tilde{\mathbf{C}}_{t+s}(\xi)=\max \int_{\Psi \backslash\left(\psi_{0}, \psi_{0}+\xi\right)}\left[\widehat{K}_{t+s}^{\alpha}(\psi)(\mathbf{z} N(\psi))^{1-\alpha}-h\left(\frac{\widehat{I}_{t+s}(\psi)}{\widehat{K}_{t+s}(\psi)}\right) \widehat{K}_{t+s}(\psi)-\widehat{C}_{t+s}(\psi)\right] d \psi-H(\overline{\mathbf{K}}) \\
\text { subject to }: \int_{\Psi \backslash\left(\psi_{0}, \psi_{0}+\xi\right)} N(\psi) d \psi=1
\end{gathered}
$$

Note that $f(\xi) \geq 0$ for all $\xi \in(0, \epsilon)$ by condition $(37)$. However, one can show that $f(\xi)$ is continuously differentiable on $(0, \epsilon)$ and

$$
f^{\prime}(0)=E_{t}\left[\int_{0}^{\infty} e^{-\mathbf{r} s}\left(\mathbf{A} \widehat{K}_{t+s}(\psi)-h\left(\frac{\widehat{I}_{t+s}(\psi)}{\widehat{K}_{t+s}(\psi)}\right) \widehat{K}_{t+s}(\psi)-\widehat{C}_{t+s}(\psi)\right) d s\right] \text { a.e. }
$$

By $(44)$, this contradicts $f(\xi) \geq 0$ for all $\xi \in(0, \epsilon)$.

\section{E Power Law of Firm Size in the First Best Case}

We first state a lemma that characterizes the stationary distribution of a Brownian motion with drift. A unit measure of particles enters the real line at $x_{0}$ at each point in time. They evaporate at a Poisson rate $\kappa$ per unit of time. Conditioning on survival, each particle follows a Brownian motion with drift after entrance:

$$
d x_{t}=\mu d t+\sigma d B_{t} .
$$

Denote the density of the stationary distribution of the particles as $m\left(x \mid x_{0}\right)$, we have:

Lemma 3. Let $\alpha_{1}>0$ and $\alpha_{2}<0$ denote the two roots of the quadratic equation, $\kappa+\mu \alpha-\frac{1}{2} \sigma^{2} \alpha^{2}=0$.

1. The stationary distribution is given by:

$$
m\left(x \mid x_{0}\right)= \begin{cases}\frac{1}{\sqrt{\mu^{2}+2 \kappa \sigma^{2}}} e^{\alpha_{2}\left(x-x_{0}\right)} & x \geq x_{0} \\ \frac{1}{\sqrt{\mu^{2}+2 \kappa \sigma^{2}}} e^{\alpha_{1}\left(x-x_{0}\right)} & x<x_{0}\end{cases}
$$

2. Assume $\kappa>\mu+\frac{1}{2} \sigma^{2}$, then $\alpha_{2}<-1$, and

$$
\int_{-\infty}^{\infty} e^{x} m\left(x \mid x_{0}\right) d y=\frac{e^{x_{0}}}{\kappa-\left(\mu+\frac{1}{2} \sigma^{2}\right)}<\infty
$$


3. The density of $X=e^{x}$, denoted $M\left(X \mid x_{0}\right)$ is given by:

$$
M\left(X \mid x_{0}\right)= \begin{cases}\frac{1}{\sqrt{\mu^{2}+2 \kappa \sigma^{2}}} e^{-\alpha_{2} x_{0}} X^{\alpha_{2}-1} & X \geq e^{x_{0}} \\ \frac{1}{\sqrt{\mu^{2}+2 \kappa \sigma^{2}}} e^{-\alpha_{1} x_{0}} X^{\alpha_{1}-1} & X<e^{x_{0}}\end{cases}
$$

In particular, the right tail of $X$ obeys power law with slope $\alpha_{2}$.

Proof. See Luttmer (2007).

Proof of proposition 2: By proposition $1, \ln K$ is a Brownian motion:

$$
d \ln K=\left(\hat{\imath}-\delta-\frac{1}{2} \sigma^{2}\right) d t+\sigma d B_{t}
$$

with initial condition $\ln \bar{K}$. Proposition 2 can be proved by applying Lemma 3 directly.

\section{F Optimal Contract Under Limited Commitment}

The following lemma completely characterizes the normalized value function, $v(u)$ and associated policy functions, $c(u)$ and $i(u)$. The proof of the lemma can be found in Ai and Li (2013).

\section{Lemma 4. (The HJB Equation)}

The normalized value function and policy functions under all three cases of limited commitment must satisfy the following HJB equation:

$$
0=\max _{c, i, g}\left\{\begin{array}{c}
{[z-c-h(i)]+v(u)[i-r-\delta]} \\
+u v^{\prime}(u)\left[\frac{r}{1-\gamma}\left(1-\left(\frac{c}{u}\right)^{1-\gamma}\right)-(i-\delta)+\frac{1}{2} \gamma g^{2} \sigma^{2}\right] \\
+\frac{1}{2} u^{2} v^{\prime \prime}(u)(g-1)^{2} \sigma^{2}
\end{array}\right\}
$$

1. In the case of limited commitment on the shareholder side, $v(u)$ is the solution to (47) on $\left(0, u_{M A X}\right]$, with the boundary condition $v\left(u_{M A X}\right)=0, v^{\prime \prime}\left(u_{M A X}\right)=\infty$, and $\lim _{u \rightarrow 0} v(u)=$ $\bar{v}$.

2. In the case of two-sided limited commitment, $u \in\left[u_{M I N}, u_{M A X}\right]$, where $v^{\prime \prime}(u)=\infty$ for $u=u_{M I N}, u_{M A X}$, and $v\left(u_{M A X}\right)=0$.

3. In the case of limited commitment on the manager side, $v(u)$ is the solution to (47) on $\left[u_{M I N}, \infty\right)$ with the boundary condition $v^{\prime \prime}\left(u_{M I N}\right)=\infty$ and $\lim _{u \rightarrow \infty} v(u)=\bar{v}-\frac{1}{\mathbf{r}+\kappa} u$.

\section{G Aggregation and the Summary Measure $m$}

In this section, we describe a procedure to solve the cross-sectional distribution of firm characteristics. We refer the reader to Ai (2012) for the technical details and proofs. Because 
firm types can be summarized by $(K, u)$, the cross-section distribution of firm characteristic can be equivalently characterized by a distribution on the $(K, u)$ space. We denote this measure by $\tilde{\Phi}(K, u)$. Using $\tilde{\Phi}(K, u)$, the resource constraints (12) and (6) can be written as:

$$
C+\int[c(u) K+h(i(u)) K] d \tilde{\Phi}(K, u)+H(\bar{K})=\int K^{\alpha}(z n(u) K)^{1-\alpha} \tilde{\Phi}(K, u),
$$

and

$$
\int n(u) K d \tilde{\Phi}(K, u)=1
$$

We define the summary measure $m$ on the space of normalized promised utility space, $(0, \infty)$. Let $m(\cdot)$ be the density such that for any Borel set $B \subseteq(0, \infty)$,

$$
\int_{B} m(u) d u=\int I_{\{u \in U, K \in(0, \infty)\}} d \tilde{\Phi}(K, u)
$$

Using the summary measure, $m(\cdot)$, the resource constraints (48) and (49) can be written as:

$$
\mathbf{C}+\int[c(u)+h(i(u))] m(u) d u+H(\bar{K})=\int(z n(u))^{1-\alpha} m(u) d u
$$

and

$$
\int n(u) m(u) d u=1
$$

respectively. Given (47), the equilibrium can be completely characterized by one-dimensional policy functions, $\{c(u), i(u), n(u)\}$ and the one dimension measure, $m(u)$.

In addition, as shown in $\mathrm{Ai}(2012), m(u)$ must satisfy the following ODE:

$$
[\kappa+\delta-i(u)] m(u)=\frac{1}{2} \sigma^{2} \frac{d^{2}}{d(\ln u)^{2}}\left\{m(u)[g(u)-1]^{2}\right\}+\frac{d}{d \ln u}\{b(u) m(u)\},
$$

where

$$
b(u)=\frac{\beta+\kappa}{1-\gamma}\left[1-\left(\frac{c(u)}{u}\right)^{1-\gamma}\right]-[i(u)-\delta]+\frac{1}{2} \sigma^{2}\left[\gamma g^{2}(u)-(g(u)-1)^{2}\right] .
$$

\section{H Limited Commitment on Manager Side Only}

We discuss briefly a version of our model with limited commitment on manager side only. Most limited commitment models in the literature consider the case of limited commitment on manager side only. The main innovation on the modeling part of the paper is limited commitment on the shareholder side. We present the solution to the model with one-sided limited commitment of the manager in this section, and highlight the importance of limited commitment on shareholder side in terms of fitting the set of stylized facts that we address in the paper. We start with the following lemma that characterize the optimal contract under limited commitment on manager side. The 
proof of the lemma can be found in $\mathrm{Ai}$ and $\mathrm{Li}$ (2013).

Lemma 5. In the case of the limited commitment on manager side,

1. Under the optimal contract, $u_{t} \geq u_{M I N}$ for all $t$. In addition, the limited commitment constraint on manager side binds if and only $u_{t}=u_{M I N}$.

2. The optimal compensation-to-capital ratio, $c\left(u_{t}\right)=\frac{C_{t}}{K_{t}}$ takes the following form:

$$
\ln c\left(u_{t}\right)=\ln C_{t}-\ln K_{t}+l_{t}^{+},
$$

where $\left\{l_{t}^{-}\right\}_{t=0}^{\infty}$ is the minimum increasing process such that $c\left(u_{t}\right) \geq c\left(u_{M A X}\right)$ for all $t$.

3. The optimal investment rate, $i(u)$ is a strictly increasing function of $u$. Also, $\lim _{u \rightarrow \infty} i(u)=$ $\hat{\imath}$, where $\hat{\imath}$ is the optimal investment level in the frictionless case.

We make several observations. First, the promised utility $u_{t}$ is bounded away from zero by $u_{M I N}$, where the limited commitment constraint binds. Second, the CEO pay-to-firm size ratio, $c\left(u_{t}\right)$ can be characterized by a regulated Brownian motion. In fact, using the result from Harrison (1985), the regulator can be constructed as:

$$
l_{t}^{+}=\max \left\{\ln c\left(u_{M I N}\right)-\ln C_{0}+\ln K_{t}^{*}, 0\right\}
$$

where $K_{t}^{*}=\sup _{0 \leq s \leq t} K_{s}$ is the running maximum of firm size up to time $t$. In this case,

$$
\ln C_{t}=\ln C_{0}+l_{t}=\max \left\{\ln c\left(u_{M I N}\right)+\ln K_{t}^{*}, \ln C_{0}\right\}
$$

or

$$
C_{t}=\max \left\{c\left(u_{M I N}\right) K_{t}^{*}, C_{0}\right\}
$$

That is, managerial compensation is a linear function of the running maximum of firm size. This characterization is consistent with the classical result of Harris and Holmstrom (1982). ${ }^{29}$ In our model, the dynamics of firm growth lead to a power law in the right tail of the distribution of firm size. Under the optimal contract, CEO pay is a linear function of the running maximum of firm size (51), which obeys a similar power law. Therefore, as we remark in Section VI, limited commitment on shareholder side is the key to generate the power law in CEO compensation. Third, because firm size is negatively correlated with normalized promised utility, $u_{t}$, the model with limited commitment on manager side produces a non-trivial elasticity of CEO pay with respect to firm size in large firms: shareholders have to raise CEO compensation to retain managers as their outside options rise with firm size. However, without limited commitment on shareholder side, the elasticity of CEO pay with respect to firm size is zero for small firms. In fact, compensation and investment policies converge to those in the first best case as firm size shrinks and $u \rightarrow \infty$. Fourth, the model

\footnotetext{
${ }^{29}$ See also Lustig, Syverson, and Van Nieuwerburgh (2011) and Grochulski and Zhang (2011).
} 
with one-sided limited commitment on manager side also produces a dependence of investment on firm size. However, the dependence of investment on firm size diminishes in small firms where $u_{t} \rightarrow \infty$, as shown in part 3 of the above lemma. In contrast, in the data, as shown in Figure 9, the investment varies considerably with firm size among small-to-medium sized firms. Quantitatively, the dependence of investment rate on firm size is very small in our calibrated model with limited commitment on manager side. As we show in Section V and VI, our model with two-sided limited commitment improves along all the above dimensions upon the model with limited commitment on manager side only.

\section{Data Description}

The cross-sectional data that we use consist of US non-financial firms and come from the Center for Research in Securities Prices (CRSP). We measure executive compensation by the total compensation figure from ExecuComp database, which comprises of salary, bonuses, the value of restricted stock granted, the Black-Scholes-based value of options granted and long-term incentive payouts. Our benchmark measure of size is based on the number of firm employees. In addition, for each firm we collect market capitalization, the book value of firms' assets, the gross value of property, plant and equipment to measure capital, capital expenditure to measure investment, and common dividends and interests on short- and long-term debt to measure total payout. We measure firm age by the number of years since the firm's founding date. Our evidence remain virtually intact if we use the date of incorporation to define firm age. Nominal quantities are converted to real using the consumer price index compiled by the Bureau of Labor Statistics. The data are sampled on the annual frequency and cover the period from 1992 till 2011.

\section{J Power-Law Estimates}

As stated in the paper, the probability distribution function of a continuous power-law random variable $x$ is given by:

$$
f(x)=k \zeta x^{-(1+\zeta)},
$$

where $k=x_{\text {min }}^{\zeta}, \quad x_{\text {min }}$ is the lower bound of the power-law behavior, and $\zeta$ is the power-law exponent. It is common in empirical work to treat $x_{\min }$ as if it were known (typically by choosing a point beyond which the empirical distribution appears approximately linear on a log-log plot) and estimate the scaling parameter $\zeta$ by maximum likelihood. However, unless the right-tail cutoff is chosen at or close to the true value, the estimates of the exponent may be significantly biased. To address this issue, we estimate both parameters by minimizing the Kolmogorov-Smirnov (KS) distance. In particular, for each potential lower bound $\tilde{x}$, we estimate the power-law exponent using the data above $\tilde{x}$ as:

$$
\tilde{\zeta}=N\left[\sum_{i=1}^{N} \ln \frac{x_{i}}{\tilde{x}}\right]^{-1}, \quad x_{i} \geq \tilde{x}, i=1, \ldots, N
$$


Our estimates of $x_{\text {min }}$ and $\zeta$ is the pair that yields the power-law distribution that provides the best fit to the observed data according to the KS criteria, i.e.,

$$
\left\{\hat{x}_{\min }, \hat{\zeta}\right\}=\min _{\tilde{x}, \tilde{\zeta}}\{K S-\text { distance }\} \equiv \min _{\tilde{x}, \tilde{\zeta}}\left\{\max _{x \geq \tilde{x}}|F(x ; \tilde{x}, \tilde{\zeta})-\hat{F}(x)|\right\}
$$

where $F(x ; \tilde{x}, \tilde{\zeta})$ is the candidate power-law cumulative distribution function and $\hat{F}(x)$ is the empirical distribution. Year-by-year estimates for size and CEO compensation are presented in Table A.1. To facilitate the comparison with Table 3, the estimates of the right-tail cutoff are quoted in terms of the number of firms in the right tail. The table also reports p-values of the Kolmogorov-Smirnov goodness-of-fit test constructed via bootstrap.

As the table shows, there is quite a lot of variation in power-law estimates across sample years. For the number of employees, the estimate of the exponent varies between 1 and 1.9, and averages about 1.26. The average of the scaling parameter of CEO compensation is about 2.1. While the mass of the right tail also varies considerably across years, interestingly, on average, the number of firms in the right tail of the size distribution is 272 , which is quite close to the 300 cutoff that we use in Table 3. For CEO compensation, the right tail amounts to just above 200 firms. Overall, the goodness-of-fit test does not reject the power-law null - the p-value is above the conventional five-percent level in $65 \%$ and $75 \%$ of sample years for size and CEO compensation, respectively. 


\section{References}

Ai, Hengjie, 2012, Aggregation in Economies with Homogenous Decision Rules, Working paper, University of Minnesota.

Ai, Hengjie, and Rui Li, 2013, Investment and CEO Compensation under Limited Commitment, Working paper, University of Minnesota.

Albuquerque, Rui, and Hugo Hopenhayn, 2004, Optimal Lending Contracts and Firm Dynamics, Review of Economic Studies 71, 285-315.

Atkeson, Andrew, and Robert Lucas, 1992, On Efficient Distribution with Private Information, Review of Economic Studies 59, 427-453.

Axtell, Robert L., 2001, Zipf Distribution of U.S. Firm Sizes, Science 293, 1818-1820.

Baker, George P., Michael C. Jensen, and Kevin J. Murphy, 1988, Compensation and Incentives: Practice vs. Theory, The Journal of Finance 43(3), 593-616.

Benhabib, Jess, Alberto Bisin, and Shenghao Zhu, 2011, The Distribution of Wealth and Fiscal Polilcy in Economies with Finitely Lived Agents, Econometrica 79, 123-157.

Biais, Bruno, Thomas Mariotti, Cuillaume Plantin, and Jean-Charles Rochet, 2004, Dynamic Security Design, Working Paper, IDEI.

Biais, Bruno, Thomas Mariotti, and Jean-Charles Rochet Stéphane Villeneuve, 2010, Large Risks, Limited Liability, and Dynamic Moral Hazard, Econometrica 78, 73-118.

Clementi, Gian, and Hugo Hopenhayn, 2006, A Theory of Financing Constraints and Firm Dynamics, Quarterly Journal of Economics 121, 229-265.

Cooley, Thomas, Ramon Marimon, and Vincenzo Quadrini, 2012, Risky Investments with Limited Commitment, Working paper.

Cooley, Thomas, and Vincenzo Quadrini, 2001, Financial Markets and Firm Dynamics, American Economic Review 91, 1286-1310.

Davis, Steven, John Haltiwanger, and Scott Schuh, 1996, Davis. (Cambridge: MIT press).

DeMarzo, Peter, and Michael Fishman, 2007a, Agency and Optimal Investment Dynamic, Review of Financial Studies 20, 151-188.

DeMarzo, Peter, and Michael Fishman, 2007b, Optimal Long-Term Financial Contracting, Review of Financial Studies 20, 2079-2128.

DeMarzo, Peter, Michael Fishman, Zhiguo He, and Neng Wang, 2009, Dynamic Agency and q Theory of Investment, Journal of Finance, Forthcoming. 
DeMarzo, Peter, and Yuliy Sannikov, 2006, Optimal Security Design and Dynamic Capital Structure in a Continuous-Time Agency Model, Journal of Finance 61, 2681-2724.

Evans, David, 1987, The Relationship between Firm Growth, Size, and Age: Estimates for 100 Manufacturing Industries, Journal of Industrial Economics 35, 567-581.

Frydman, Carola, and Raven Saks, 2010, Executive Compensation: A New View from a Long-Run Perspective, 1936-2005, Review of Financial Studies 23, 2099-2138.

Gabaix, Xavier, 2009, Power Laws in Economics and Finance, Annual Review of Economics 1, $255-293$.

Gabaix, Xavier, and Augustin Landier, 2008, Why Has CEO Pay Increased So Much?, Quarterly Journal of Economics 123, 49-100.

Gibrat, Robert, 1931, Les Inegalites Economiques. (Paris, France: Librairie du Recueil Sirey, 1931).

Grochulski, Borys, and Yuzhe Zhang, 2011, Optimal risk sharing and borrowing constraints in a continuous-time model with limited commitment, Journal of Economic Theory 146, 2356-2388.

Hall, Bronwyn, 1987, The reslationship between firm size and firm growth in the US manufacturing sector, The journal of industrial economics 35, 583-606.

Harris, Milton, and Bengt Holmstrom, 1982, A Theory of Wage Dynamics, Review of Economic Studies XLIX, 315-333.

Harrison, Michael, 1985, Brownian Motion and Stochastic Flow Systems. (John Wiley and Sons).

Hayashi, Fumio, 1982, Tobin's Marginal q and Average q: A Neoclassical Interpretation, Econometrica 50, 213-224.

He, Zhiguo, 2009, Optimal Executive Compensation when Firm Size Follows Geometric Brownian Motion, Review of Financial Studies 22, 859-892.

Kehoe, Timothy, and David Levine, 1993, Debt-Constrained Asset Markets, Review of Economic Studies 60, 865-888.

Kesten, Harry, 1973, Random Difference Equations and Renewal Theory for Products of Random Matrices, Acta Mathematica 131, 207-248.

Kiyotaki, Nobuhiro, and John Moore, 1997, Credit Cycles, Journal of Political Economy 105, 211284.

Kocherlakota, Narayana, 1996, Implications of Efficient Risk Sharing without Commitment, Review of Economic Studies 63, 595-609. 
Lorenzoni, Guido, and Karl Walentin, 2007, Financial Frictions, Investment and Tobin's q, Working paper, MIT.

Lustig, Hanno, Chad Syverson, and Stijn Van Nieuwerburgh, 2011, Technological Change and the Growing Inequality in Managerial Compensation, Journal of Financial Economics.

Luttmer, Erzo, 2007, Selection, Growth, and the Size Distribution of Firms, Quarterly Journal of Economics 122, 1103-1144.

Luttmer, Erzo, 2010, Models of growth and firm Heterogeneity, Annual Review of Economics 2, $547-576$.

Miao, Jianjun, and Yuzhe Zhang, 2013, A duality approach to continuous-time contracting problems with limited commitment, Working paper, Boston University.

Piskorski, Tomasz, and Alexei Tchistyi, 2010, Optimal Mortgage Design, Review of Financial Studies 23, 3098-3140.

Quadrini, Vincenzo, 2004, Investment and Liquidation in Renegotiation-Proof Contracts with Moral Hazard, Journal of Monetary Economics 51, 713-751.

Rampini, Adriano, and S. Viswanathan, 2010, Collateral, risk management, and the distribution of debt capacity, Journal of Finance 65, 2293-2322.

Rampini, Adriano, and S. Viswanathan, 2012, Collateral and capital structure, Working paper, Duke University.

Roberts, David R., 1956, A General Theory of Executive Compensation Based on Statistically Tested Propositions, The Quaterly Journal of Economics 70(2), 270-294.

Sannikov, Yuliy, 2008, A Continuous-Time Version of the Principal-Agent Problem, Review of Economic Studies 75, 957-984.

Saporta, B., 2005, Tail of the stationary solution of the stochastic equation $Y_{n+1}=a_{n} Y_{n}+b_{n}$ with Markovian coefficients, Stochastic Processes and Their Applications 115, 1954-1978.

Schmid, Lukas, 2008, A Quantitative Dynamic Agency Model of Financing Constraints, Working paper, Duke University.

Tchistyi, Alexei, 2006, Security Design with Correlated Hidden Cash Flows: The Optimality of Performance Pricing, Working Paper, University of California, Berkeley.

Tervio, Marko, 2003, The Difference That CEOs Make: An Assignment Model Approach, Working paper, University of California, Berkeley. 
Weil, Philippe, 1989, The Equity Premium Puzzle and the Risk-Free Rate Puzzle, Journal of Monetary Economics 24, 401-421.

Zhu, John, Forthcoming, Optimal Contracts with Shirking, Review of Economic Studies. 
Table 1

\section{Model Parameters}

\begin{tabular}{lcc}
\hline \hline Description & Notation & Value \\
\hline Risk aversion & $\gamma$ & 2 \\
Discount rate & $\beta$ & 0 \\
Capital share & $\alpha$ & 0.33 \\
Marginal product of capital & $\mathbf{A}$ & 0.224 \\
Adjustment cost & $\phi$ & 5 \\
Productivity growth rate & $\mu$ & $2 \%$ \\
Volatility & $\sigma$ & $35 \%$ \\
Firm death rate & $\kappa$ & $5 \%$ \\
Capital depreciation & $\delta$ & $7 \%$ \\
\hline \hline
\end{tabular}

Table 1 presents calibration of the key model parameters. 
Table 2

Targeted Moments

\begin{tabular}{lc}
\hline \hline Moment (mean) & Value \\
\hline Aggregate Growth & $2 \%$ \\
Rate of Return & $4 \%$ \\
Tobin's Q & 1.7 \\
Total Capital Depreciation & $12 \%$ \\
Volatility of Sales Growth & $35 \%$ \\
Aggregate Investment-to-Output Ratio & $20 \%$ \\
Aggregate CEO Pay-to-Output Ratio & $1.4 \%$ \\
\hline \hline
\end{tabular}

Table 2 shows the model-implied moments that are targeted in calibration. 
Table 3

Estimates of the Power Law Exponent of Firm Size and CEO Compensation

\begin{tabular}{ccc}
\hline \hline Year & Size & CEO Comp \\
\hline 1992 & 1.06 & 1.68 \\
1993 & 1.13 & 1.73 \\
1994 & 1.20 & 1.77 \\
1995 & 1.18 & 1.63 \\
1996 & 1.18 & 1.61 \\
1997 & 1.15 & 1.42 \\
1998 & 1.17 & 1.58 \\
1999 & 1.15 & 1.32 \\
2000 & 1.12 & 1.22 \\
2001 & 1.06 & 1.35 \\
2002 & 1.05 & 1.53 \\
2003 & 1.05 & 1.60 \\
2004 & 1.04 & 1.69 \\
2005 & 1.10 & 1.63 \\
2006 & 1.10 & 1.76 \\
2007 & 1.09 & 1.81 \\
2008 & 1.10 & 1.93 \\
2009 & 1.08 & 2.05 \\
2010 & 1.07 & 2.23 \\
2011 & 1.09 & 2.05 \\
\hline \hline
\end{tabular}

Table 3 presents the power-law exponent of firm size and CEO compensation estimated using the largest 300 firms in a given year. Size in the data is measured by the number of firm employees. 
Table 4

Elasticity of CEO Compensation with respect to Firm Size

\begin{tabular}{lcccc}
\hline \hline & \multicolumn{4}{c}{ Size Measures } \\
& Employees & Market Cap & Capital & Assets \\
\hline Elasticity & 0.31 & 0.33 & 0.28 & 0.37 \\
SE & 0.02 & 0.02 & 0.02 & 0.02 \\
$R^{2}$ & 0.20 & 0.27 & 0.20 & 0.23 \\
\hline \hline
\end{tabular}

Table 4 reports estimates of the elasticity of CEO compensation with respect to firm size. We consider several measures of firm size: the number of employees ("Employees"), market capitalization ("Market Cap"), book value of capital ("Capital"), and book value of assets ("Assets"). 
Table 5

Distribution of CEO Compensation across Size and Age

Panel A: Data

\begin{tabular}{lccc}
\hline \hline & \multicolumn{3}{c}{ Age } \\
\cline { 2 - 4 } Size & Young & Median & Old \\
\hline Small & 10.2 & 8.1 & 6.4 \\
Median & 13.6 & 12.4 & 7.9 \\
Large & 18.8 & 29.4 & 24.0 \\
\hline \hline
\end{tabular}

Panel B: Model

\begin{tabular}{lccc}
\hline \hline & \multicolumn{3}{c}{ Age } \\
\cline { 2 - 4 } Size & Young & Median & Old \\
\hline Small & 4.8 & 3.4 & 2.7 \\
Median & 5.7 & 5.0 & 4.4 \\
Large & 5.8 & 7.0 & 28.6 \\
\hline \hline
\end{tabular}

Table 5 presents the distribution of CEO compensation across firms of different size and age. Panel A reports average CEO compensation in the data, Panel B presents model-implied statistics. Size in the data is measured by the number of firm employees. 
Table 6

Distribution of CEO Pay-to-Capital across Size and Age

Panel A: Data

\begin{tabular}{lccc}
\hline & \multicolumn{3}{c}{ Age } \\
\cline { 2 - 4 } Size & Young & Median & Old \\
\hline Small & 0.123 & 0.075 & 0.042 \\
Median & 0.022 & 0.023 & 0.016 \\
Large & 0.014 & 0.011 & 0.008 \\
\hline \hline
\end{tabular}

\section{Panel B: Model}

\begin{tabular}{lccc}
\hline \hline & \multicolumn{3}{c}{ Age } \\
\cline { 2 - 4 } Size & Young & Median & Old \\
\hline Small & 0.096 & 0.080 & 0.070 \\
Median & 0.046 & 0.034 & 0.029 \\
Large & 0.013 & 0.007 & 0.005 \\
\hline \hline
\end{tabular}

Table 6 presents the cross-sectional variation of the ratio of CEO compensation to capital. Panel A reports data moments, Panel B presents model-implied statistics. Size in the data is measured by the number of firm employees. 
Table 7

Distribution of $\mathrm{I} / \mathrm{K}$ across Size and Age

Panel A: Data

\begin{tabular}{lccc}
\hline \hline & \multicolumn{3}{c}{ Age } \\
\cline { 2 - 4 } Size & Young & Median & Old \\
\hline Small & 0.24 & 0.19 & 0.14 \\
Median & 0.17 & 0.16 & 0.10 \\
Large & 0.16 & 0.14 & 0.11 \\
\hline \hline
\end{tabular}

Panel B: Model

\begin{tabular}{lccc}
\hline \hline & \multicolumn{3}{c}{ Age } \\
\cline { 2 - 4 } Size & Young & Median & Old \\
\hline Small & 0.24 & 0.20 & 0.19 \\
Median & 0.16 & 0.15 & 0.15 \\
Large & 0.14 & 0.14 & 0.13 \\
\hline \hline
\end{tabular}

Table 7 presents the cross-sectional distribution of investment-to-capital ratio. Panel A reports average I/K in the data, Panel B presents model-implied statistics. Size in the data is measured by the number of firm employees. 
Table A.1

Estimates of the Power-Law Parameters of Firm Size and CEO Compensation

\begin{tabular}{|c|c|c|c|c|c|c|}
\hline \multirow[t]{2}{*}{ Year } & \multicolumn{3}{|c|}{ Size } & \multicolumn{3}{|c|}{ CEO Compensation } \\
\hline & Exponent & Right-Tail & $\mathrm{P}$-value & Exponent & Right-Tail & P-value \\
\hline 1992 & 1.89 & 49 & 0.57 & 1.60 & 381 & 0.00 \\
\hline 1993 & 1.34 & 170 & 0.07 & 2.54 & 89 & 0.30 \\
\hline 1994 & 1.12 & 385 & 0.01 & 2.21 & 137 & 0.09 \\
\hline 1995 & 1.16 & 345 & 0.00 & 2.38 & 145 & 0.88 \\
\hline 1996 & 1.54 & 138 & 0.43 & 2.02 & 164 & 0.13 \\
\hline 1997 & 1.37 & 203 & 0.08 & 1.56 & 239 & 0.17 \\
\hline 1998 & 1.00 & 728 & 0.09 & 1.59 & 311 & 0.04 \\
\hline 1999 & 1.01 & 625 & 0.09 & 1.47 & 194 & 0.20 \\
\hline 2000 & 1.06 & 475 & 0.04 & 1.90 & 68 & 0.69 \\
\hline 2001 & 1.02 & 428 & 0.07 & 1.88 & 99 & 0.69 \\
\hline 2002 & 1.29 & 167 & 0.02 & 1.56 & 328 & 0.00 \\
\hline 2003 & 1.12 & 292 & 0.00 & 3.12 & 61 & 0.62 \\
\hline 2004 & 1.34 & 166 & 0.07 & 3.14 & 70 & 0.73 \\
\hline 2005 & 1.29 & 192 & 0.04 & 1.50 & 423 & 0.00 \\
\hline 2006 & 1.26 & 198 & 0.06 & 2.55 & 120 & 0.71 \\
\hline 2007 & 1.33 & 180 & 0.37 & 2.07 & 227 & 0.22 \\
\hline 2008 & 1.32 & 175 & 0.40 & 2.34 & 108 & 0.53 \\
\hline 2009 & 1.28 & 177 & 0.02 & 2.06 & 316 & 0.06 \\
\hline 2010 & 1.21 & 211 & 0.12 & 2.21 & 347 & 0.08 \\
\hline 2011 & 1.32 & 134 & 0.09 & 2.36 & 203 & 0.00 \\
\hline
\end{tabular}

Table A.1 presents the estimates of the exponent and the right-tail mass of power-law distribution for firm size and CEO compensation, and p-values of the Kolmogorov-Smirnov goodness-of-fit test. The right tail is quoted in terms of the number of firms in the right tail. Size in the data is measured by the number of firm employees. 


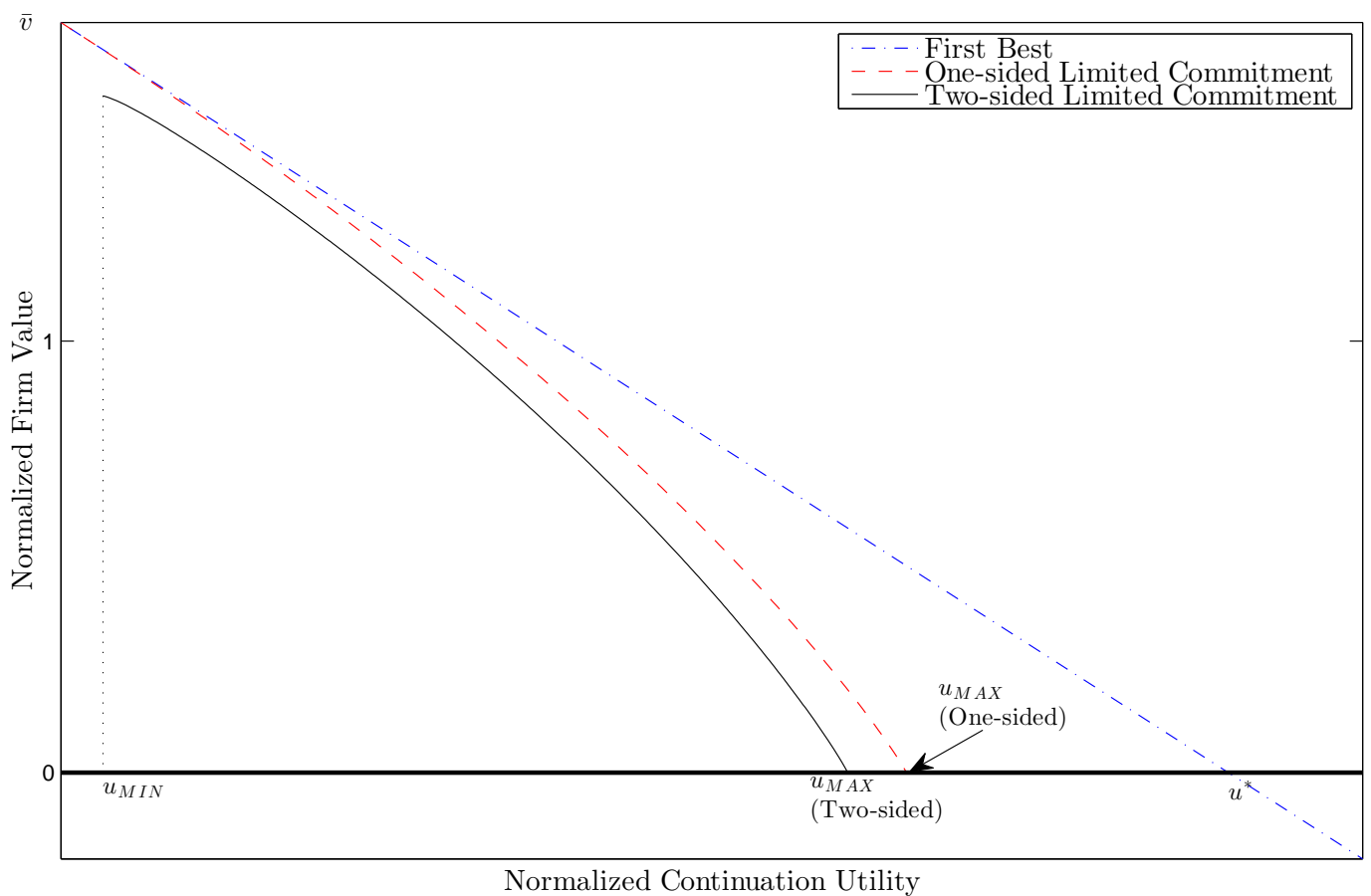

Figure 1. Normalized Value Function: First Best and One-sided Limited Commitment

Figure 1 plots the normalized value function for the first best case (dash-dotted line) and that for the case of limited commitment on shareholder side (dashed line). $\bar{v}$ is the marginal/average Q in the Hayashi (1982) model. The domain of the normalized value function for the first best case is $[0, \infty)$ and $u^{*}$ is the point where $v(u)$ crosses zero. With limited commitment on manager side, the domain of the normalized value function is $\left[0, u_{M A X}\right)$, where value function stays non-negative. At the bankruptcy point, $u_{M A X}$, normalized continuation utility returns to the interior with probability one. 


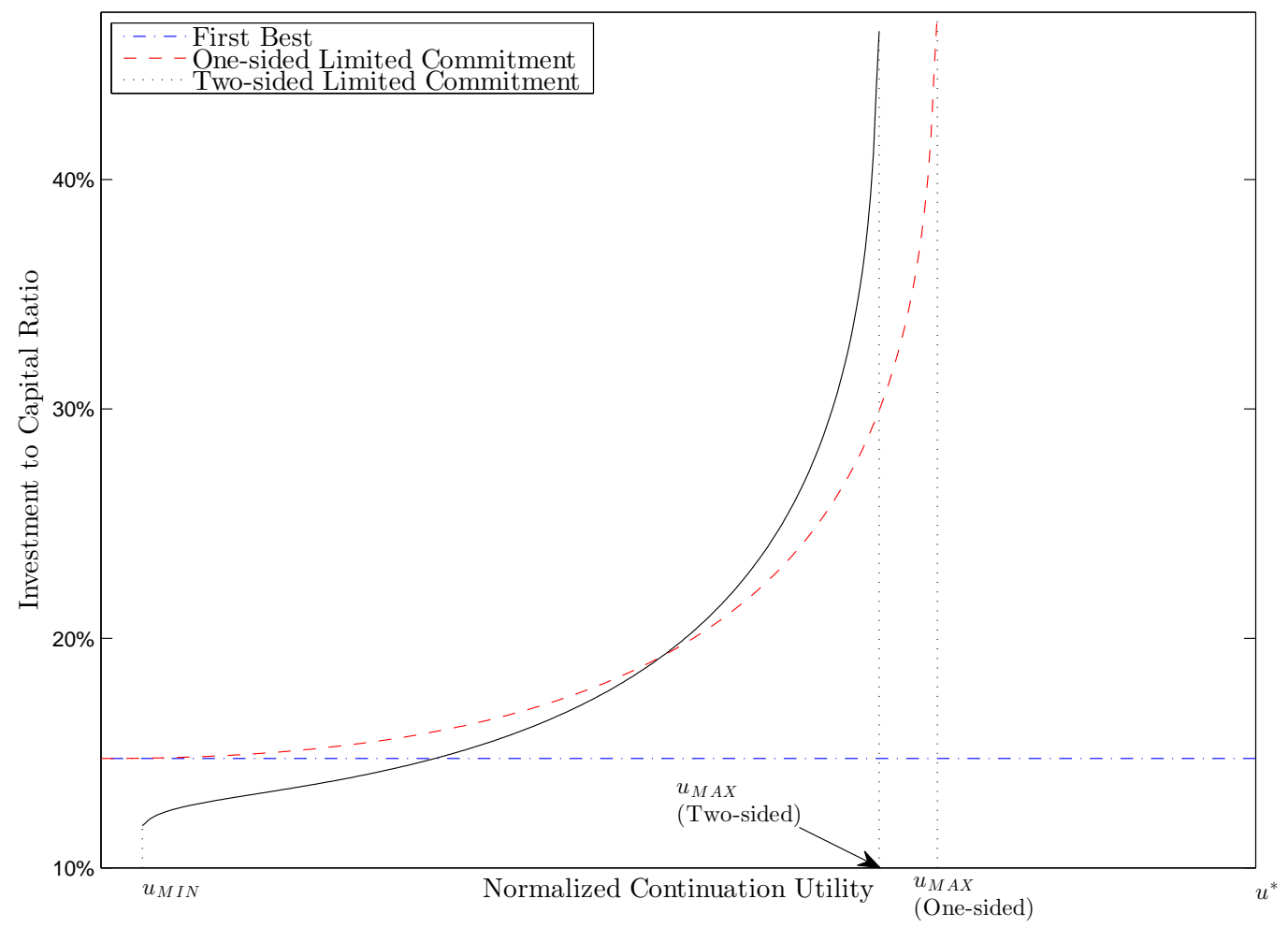

Figure 2. Investment Policy: First Best and One-Sided Limited Commitment

Figure 2 plots the optimal investment rate $\left(\frac{I}{K}\right)$ as a function of the state variable $u$ for the fist best case (dash-dotted line) and for the case with one-sided limited commitment (dashed line). The investment rate in the limited commitment case is monotonically increasing in normalized continuation utility, $u$, and converges to the first best level as $u \rightarrow 0$. 

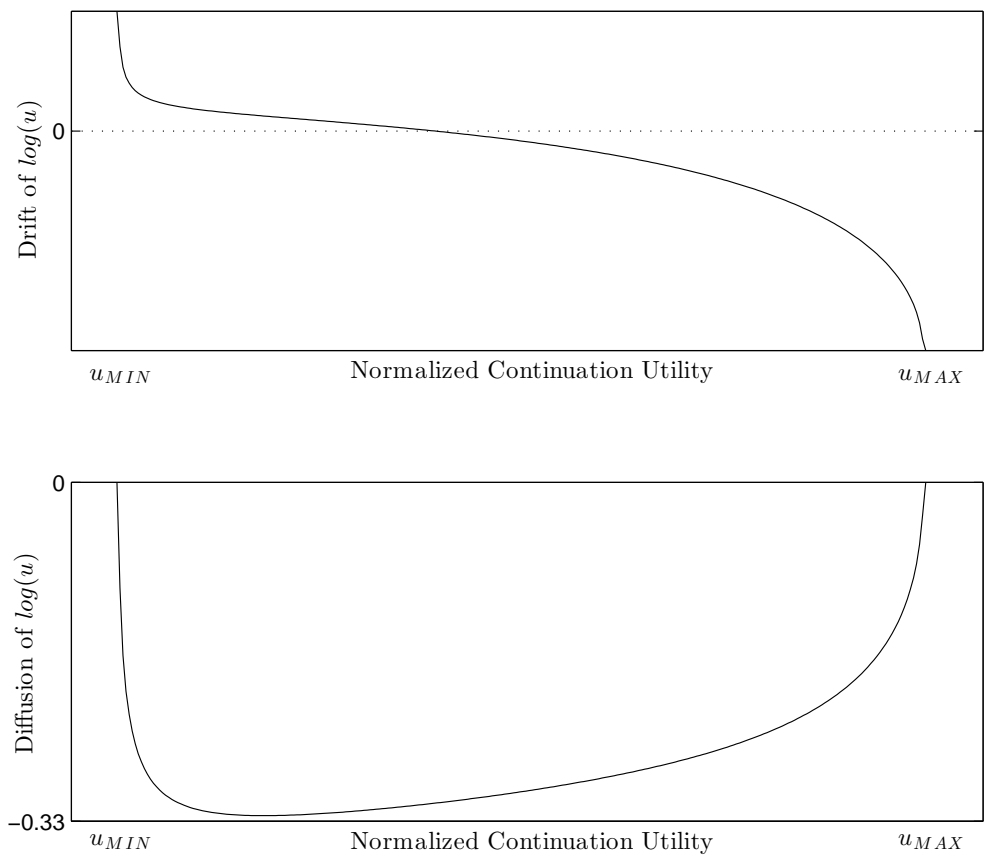

Figure 3. Dynamics of Normalized Continuation Utility: Two-Sided Limited Commitment

Figure 3 illustrates the dynamics of the normalized continuation utility, $u$, for the case of two-sided limited commitment. The drift of $u$ is strictly positive on the left, monotonically decreasing, and strictly negative on the right. The diffusion is zero on the boundaries and strictly negative in the interior. 

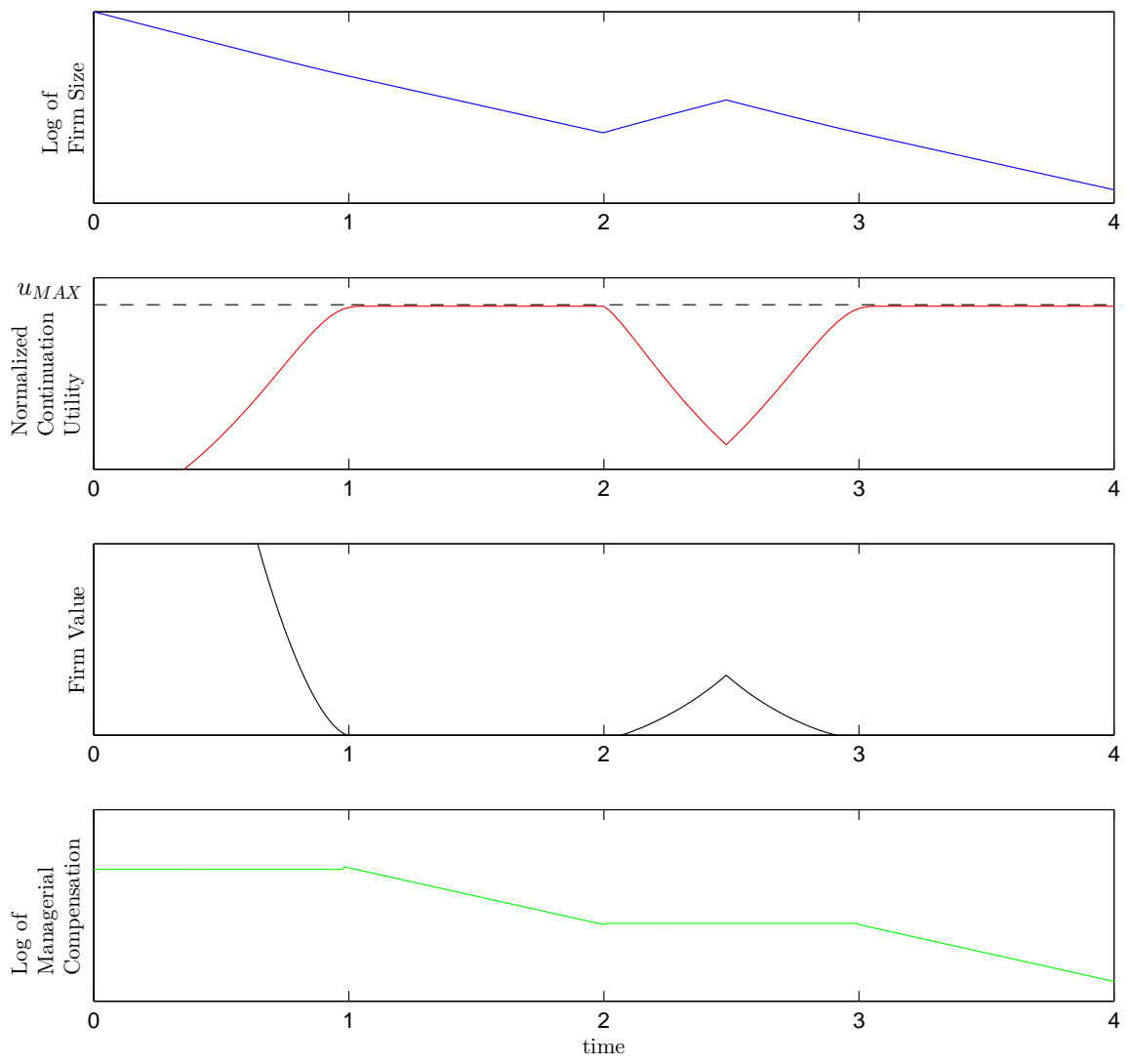

Figure 4. Sample Path of CEO Compensation: The Bankruptcy Constraint

Figure ?? plots the sample paths of firm size (top panel), normalized continuation utility (second panel), firm value (third panel), and log CEO pay (bottom panel) in the neighborhood of the bankruptcy point, $u_{M A X}$ after a sequence of productivity shocks from time 0 to time 4 . 

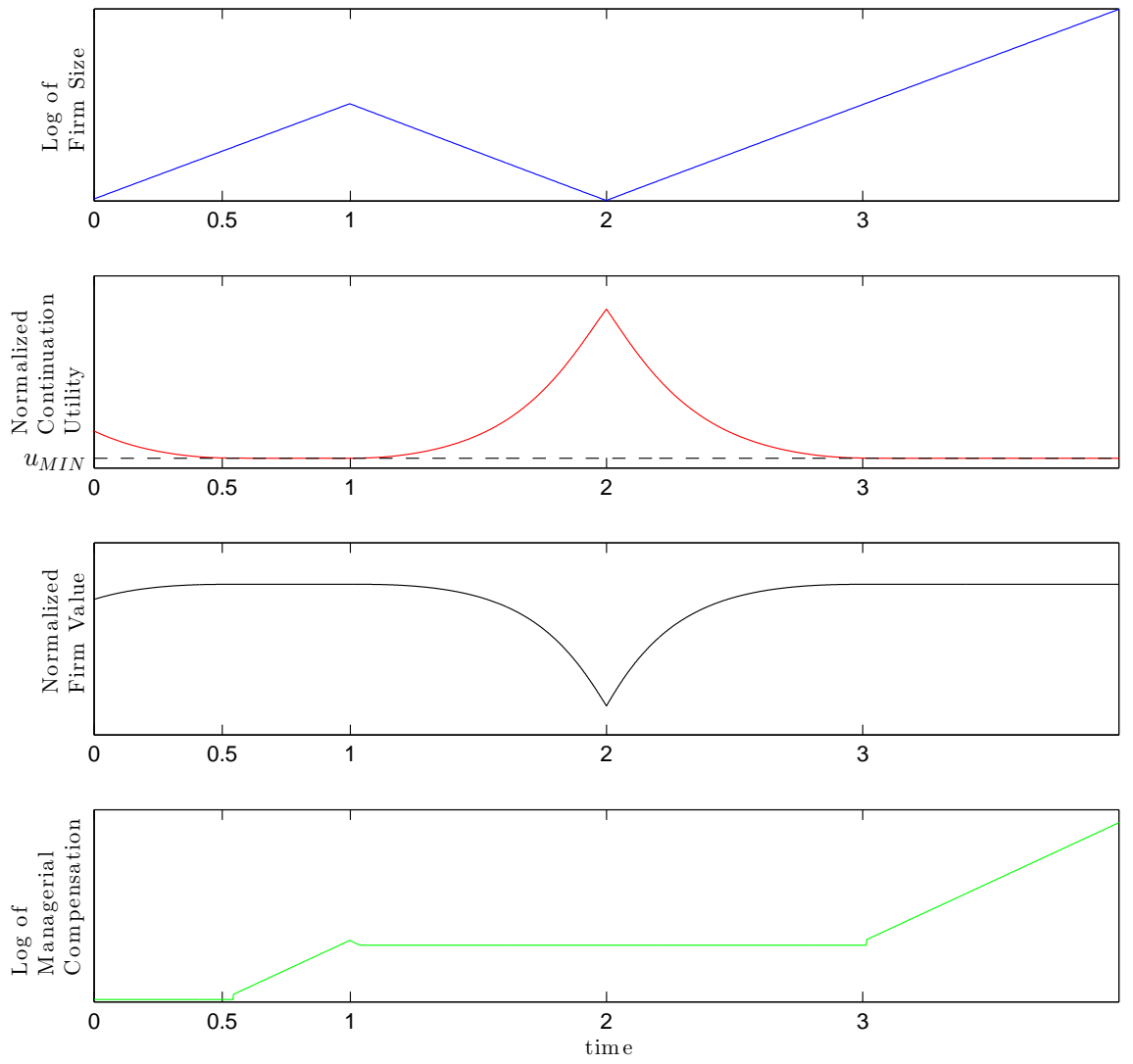

Figure 5. Sample Path of CEO Compensation: The Participation Constraint

Figure 5 plots the sample paths of firm size (top panel), normalized continuation utility (second panel), firm value (third panel), and log CEO pay (bottom panel) in the neighborhood of the binding participation constraint, $u_{M I N}$, after a sequence of productivity shocks from time 0 to time 4 . 


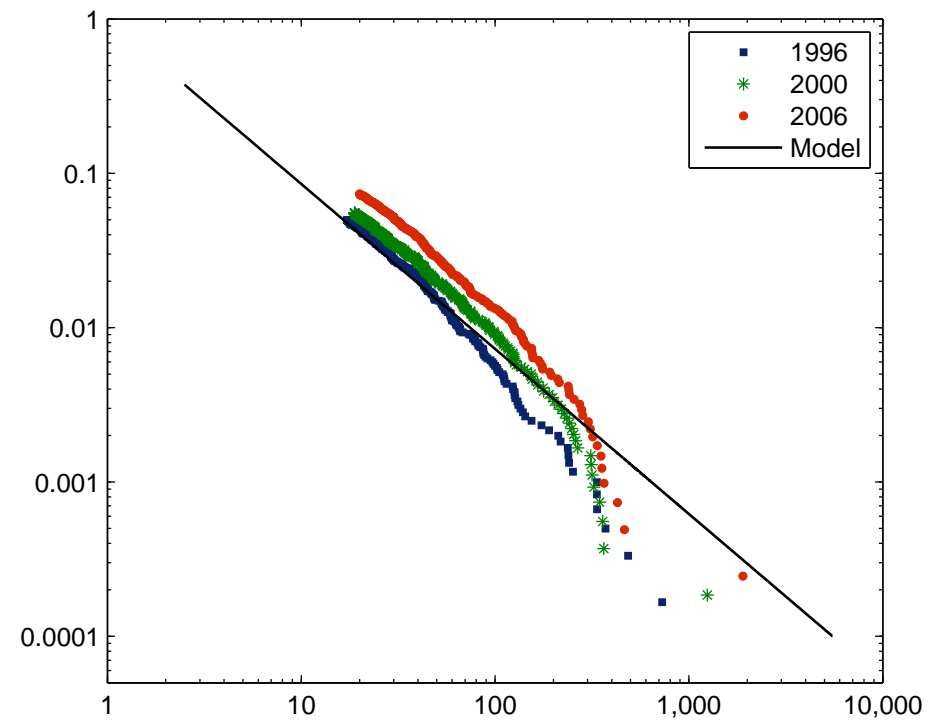

Figure 6. The Right Tail of Size Distribution

Figure 6 plots the right tail of size distribution in the data (for 1996, 2000 and 2006) and the slope implied by the model. Size is measured by the number of firm employees (in thousands). 


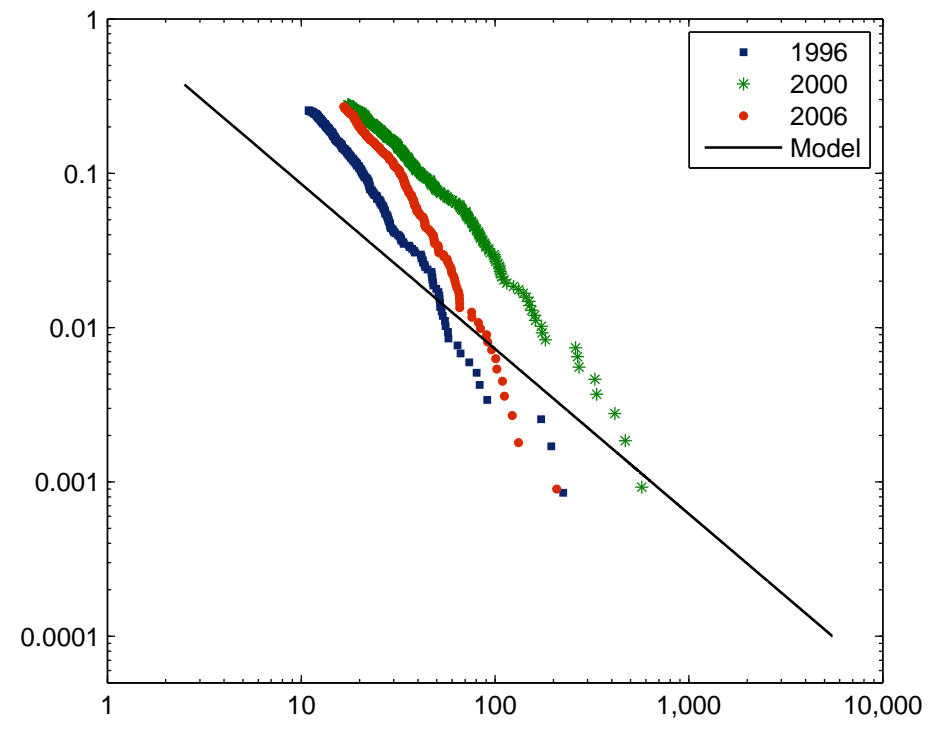

Figure 7. The Right Tail of the Distribution of CEO Compensation

Figure 7 plots the right tail of the distribution of CEO compensation in the data (for 1996, 2000 and 2006) and the slope implied by the model. CEO compensation is measured in million of dollars. 


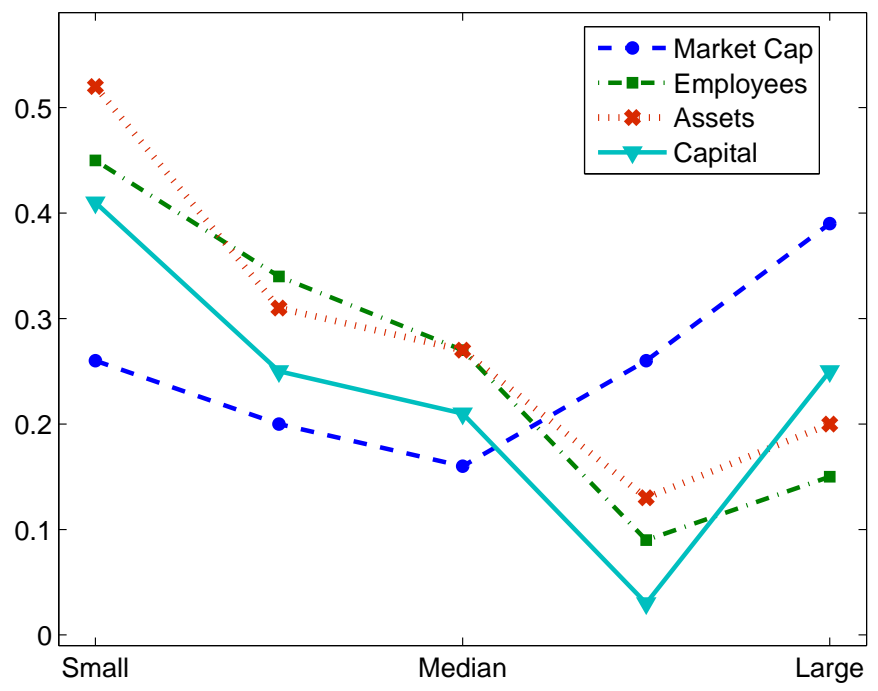

(a) Data

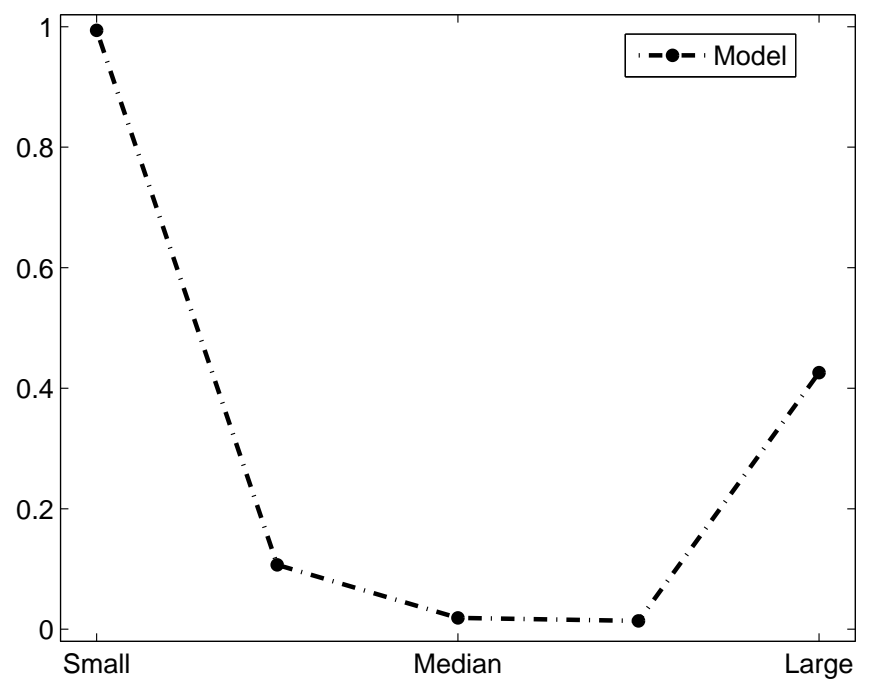

(b) Model

Figure 8. Elasticity of CEO Compensation w.r.to Size conditional on Size

Figure 8 plots the estimates of elasticity of CEO compensation with respect to firm size in the data (Panel (a)) and in the model (Panel (b)). We consider several measures of firm size in the data: market capitalization ("Market Cap"), the number of employees ("Employees"), total capital stock ("Capital"), and book value of assets ("Assets"). 


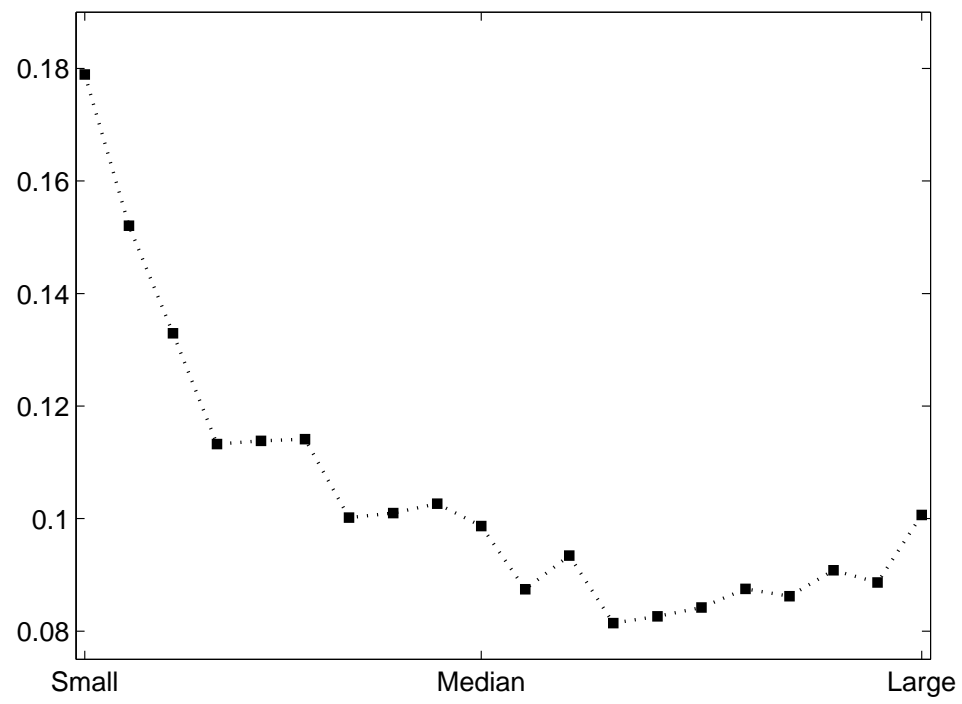

(a) Data

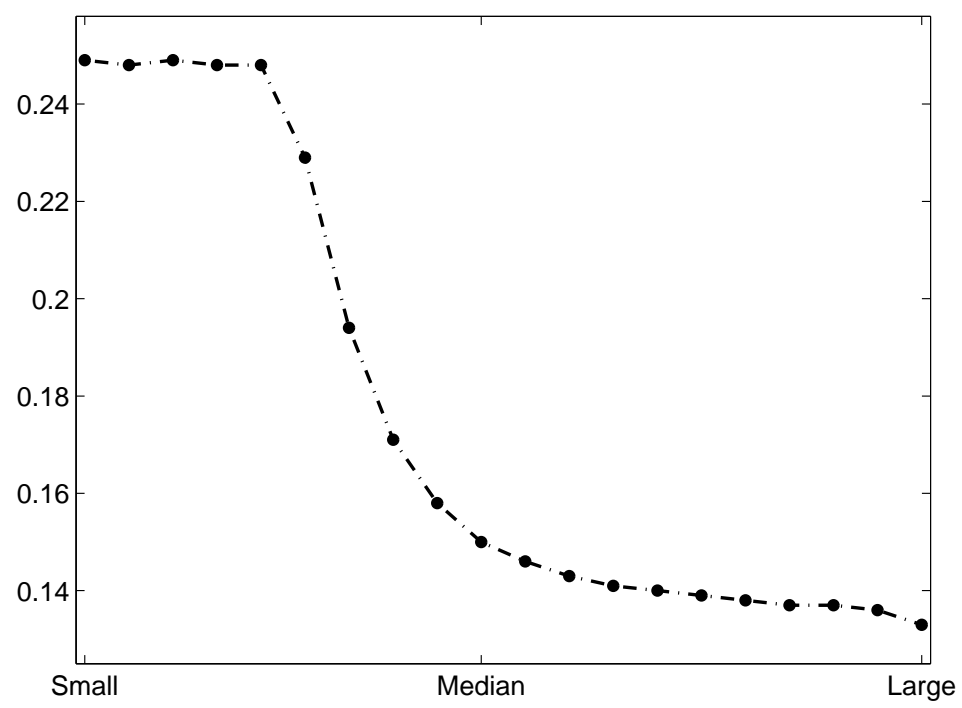

(b) Model

Figure 9. Investment-to-Capital Ratio across Size Percentiles

Figure 9 plots the average ratio of investment to capital across 20 size-sorted portfolios. In the data, size is measured by the number of firm employees. 


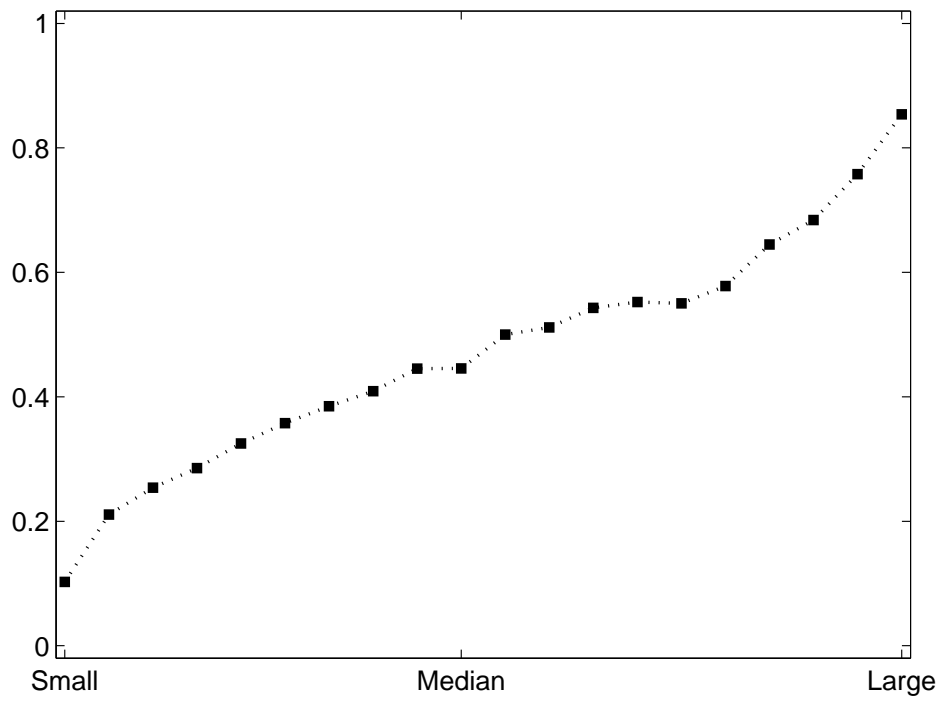

(a) Data

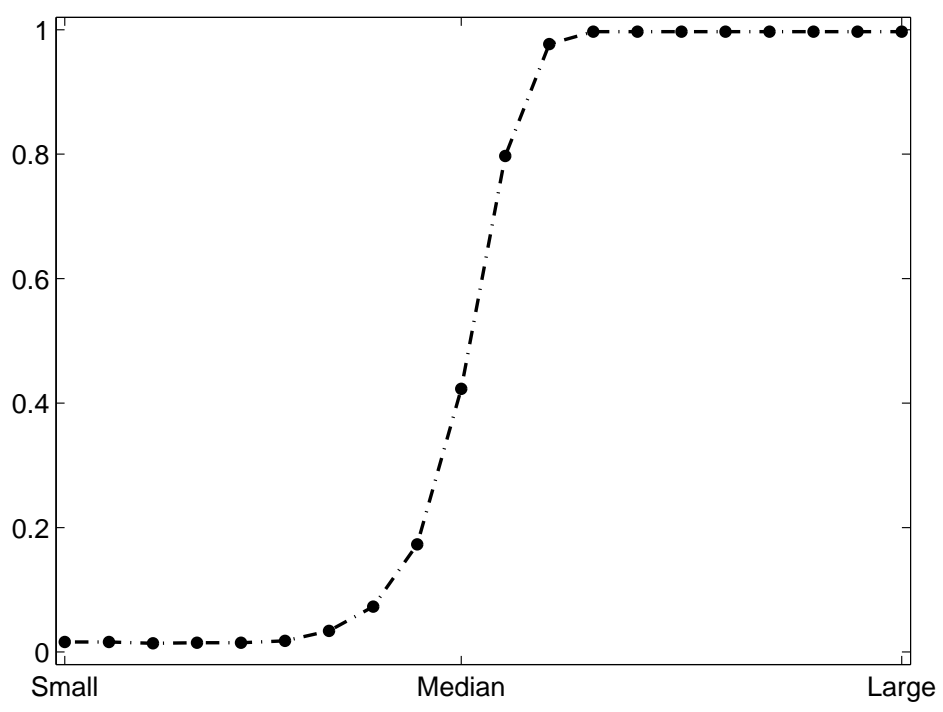

(b) Model

Figure 10. Fraction of Dividend(Interest)-Paying Firms across Size Percentiles

Figure 10 plots the fraction of firms that make dividend and/or interest payments across 20 size-sorted portfolios. In the data, size is measured by the number of firm employees. 